\title{
ENTRE EL CIELO Y LA TIERRA. NATURALEZA ANTROPOMÓRFICA EN LA OBRA DE VICTORIA CANO
}

\author{
BETWEEN HEAVEN AND EARTH. ANTHROPOMORPHIC NATURE IN \\ THE WORK OF VICTORIA CANO
}

\author{
Nieves Alberola Crespo \\ Universitat Jaume I de Castelló \\ Vicent F. Zuriaga Senent \\ Universidad Católica de Valencia
}

ABSTRACT • In 2016, an anthological exhibition of the work of the painter Victoria Cano was held at the Centro del Carmen in Valencia. The exhibition was entitled Ecos y huellas. Desde el Trastevere al Carmen and it was sponsored by the Consorci de Museus de la Generalitat Valenciana. It brought recognition to the long and distinguished career of one of the best contemporary Spanish artists. Victoria Cano's talent allowed her to enjoy a two-year research scholarship at the Academia Española de Bellas Artes de Roma in the early 80's. During her stay (19811983), Victoria Cano was the only woman to be awarded the scholarship, the rest of students were all men. Cano earned a PhD in Fine Arts (1988) and shortly after was named Professor at the School of Fine Arts in Valencia. Since 1988 her career trajectory has included a multitude of national and international shows. Her works have been exhibited in China, South Korea, New York, Murano, Milan, Rome, Berlin and Bangladesh. We met the artist at her studio, interviewed her and studied her work. This article aims at reviewing the fundamental milestones of her artistic itinerary and revealing the essence of her artistic production.

KEYWORDS: Victoria Cano; Footprints; Senses; Nature; Environment; New Technologies; Human Beings; Gender Violence; Profiles; Roots; City.

RESUMEN • En 2016 tuvo lugar una exposición antológica de la obra de la pintora Victoria Cano en el Centro del Carmen de Valencia titulada Ecos y huellas. Desde el Trastevere al Carmen. Promovida por el Consorci de Museus de la Generalitat Valenciana, la exposición supuso el reconocimiento a la larga trayectoria de una de las mejores artistas españolas contemporáneas. El talento y la labor de producción e investigación de Victoria Cano le permitió disfrutar a principios de los 80 de una beca de pensionado de dos años en la Academia Española de Bellas Artes de Roma. Destacar que durante su estancia (1981-1983) fue la única mujer pensionada, el resto de compañeros eran hombres. Doctora (1988) y Profesora titular de la Facultad de Bellas Artes de Valencia, desde 1988 su trayectoria se ha consolidado por multitud de exposiciones nacionales e internacionales con obra en instituciones públicas y privadas de medio mundo. El presente artículo es fruto de una larga entrevista en la que, en diálogo con la artista, repasamos los hitos fundamentales de su trayectoria artística y la esencia de sus creaciones.

PALABRAS CLAVES: Victoria Cano; Huellas; Sentidos; Naturaleza; Medio ambiente; Nuevas tecnologías; Ser humano; Violencia de género; Perfiles; Raíces; Ciudad.

Fecha recepción: 1-10-2018 / Fecha aceptación: 25-10-2018 
La exposición antológica de 2016, promovida por el Consorci de Museus de la Generalitat Valenciana y celebrada en el Centre del Carmen de Valencia, supuso el reconocimiento a una de las mejores artistas españolas contemporáneas. La transformación de la antigua Escuela de Bellas Artes de Valencia, situada en lo que hoy es el Centro Cultural del Carmen, consagró el regreso de una antigua alumna oriunda de Alcalá la Real (Jaén) que se formó en aquellas aulas. Al igual que a otros grandes maestros valencianos, el talento y la labor de producción e investigación de Victoria Cano le permitió disfrutar a principios de los 80 de una beca de pensionado de dos años en la Academia Española de Roma. Destacar que durante su estancia (1981-1983) fue la única mujer pensionada, el resto de compañeros eran hombres. Doctora y profesora titular de la Facultad de Bellas Artes de Valencia desde 1988 su trayectoria se ha consolidado por multitud de exposiciones nacionales e internacionales con obra en instituciones públicas y privadas de medio mundo.

Como conservadores del MACVAC tuvimos la suerte de dialogar brevemente con ella en la inauguración de su exposición en el Museo de Arte Contemporáneo de Vilafamés titulada La Huella de los sentidos (2018). A nuestras preguntas contestaba con el entusiasmo y generosidad que la caracterizan. El tiempo era limitado para intercambiar información sobre «huellas" y "perfiles» desde "el Trastévere al Carmen». Por ello concertamos una visita a su vivienda-estudio situado en la calle del Portal de la Valldigna (Valencia). Mientras algunas de sus creaciones se podían contemplar en la XVIII Bienal de Asia de Bangladesh en septiembre de 2018, nosotros encaminábamos nuestros pasos hacia el número 7 . Lo primero que llamó nuestra atención fueron los murales exteriores en los que ha transformado la fachada, que entendemos como homenaje de la pintora al barrio que la alberga y referente emocional de la artista. Una gran ola a modo de tsunami recorre el zócalo al tiempo que sirve de unión a las distintas escenas pintadas.

Nieves Alberola: ${ }^{1}$ Son numerosos los temas que tratas en tu obra. ¿Podrías decirnos cuál consideras que es el fundamental?

Victoria Cano: El tema fundamental de mi trabajo es la energía puesto que la creación artística la concibo como la energía con la que intento atrapar vivencias y transportarlas no solo a lienzos o libros artísticos sino también a las paredes de la fachada de mi estudio. Por ejemplo, en 2016 empecé a pintar en el zócalo el agua pues es un elemento que está presente en muchas de mis obras junto con el fuego, la naturaleza, el ser humano dentro de la naturaleza [...] No debemos olvidar que el agua en nosotros es un elemento importantísimo; al nacer nuestro cuerpo posee alrededor de un $70 \%$ de agua. Comencé a pintar en las puertas olas, con perfiles humanos. En 2017 con motivo del 60 aniversario de la riada de Valencia (1957) e inspirada por la obra Amor de Madre de Muñoz Degrain, pinté este mural [fig. 1], en el que el agua aparece como fuerza destructora. Tomé de modelo a un bebé del barrio; la madre, y toda la familia, vive aquí cerca y le pedí que posara. Hice esa interpretación porque el amor de madre es atemporal como la naturaleza. La naturaleza y el ser humano están siempre en constante transformación. En este sentido las burbujas que aparecen en el agua son burbujas de oxígeno para el barrio. En el lateral podemos ver otro mural en el que una abuela y su nieta son las protagonistas [fig. 2], también vecinas del barrio. Gracias a esta composición hago alusión al paso del tiempo y esa transformación queda aquí registrada.

1. Conservadora del Museo de Arte Contemporáneo de Vilafamés MACVAC. Investigadora del Grupo Lenguas y Culturas Europeas y Nuevos Lenguajes Literarios y Audiovisuales (Universitat Jaume I) e investigadora del Grupo Investigación en Estudios Feministas y de Género (Universitat Jaume I). 


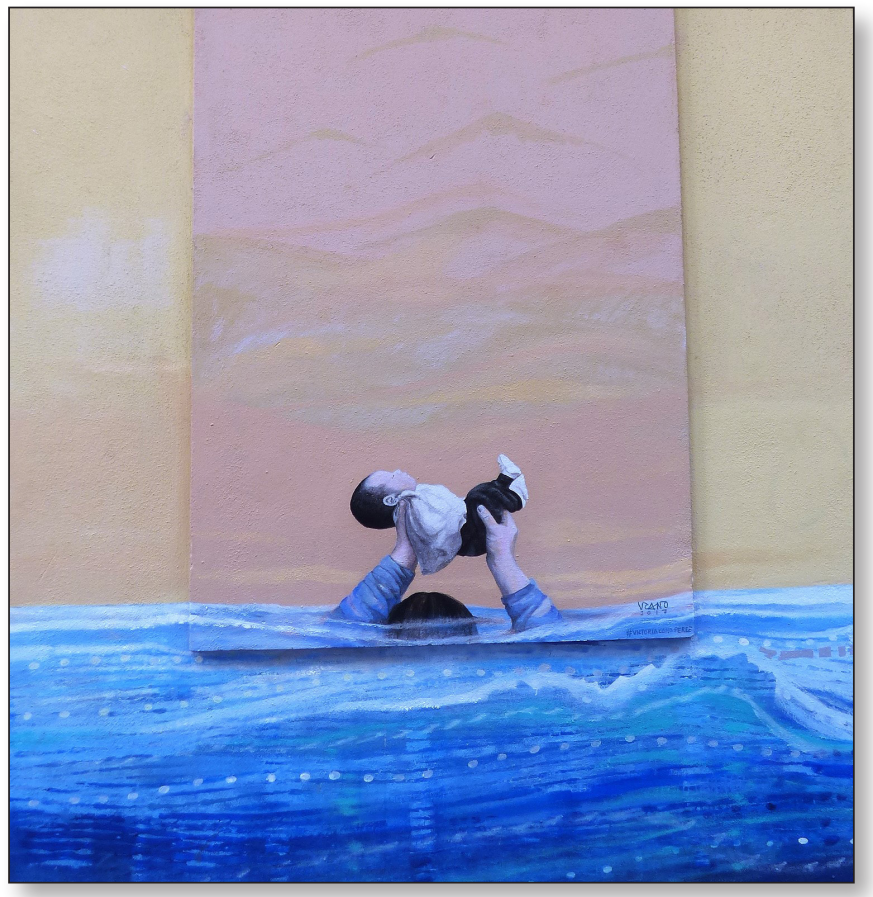

Fig. 1. Amor de madre.

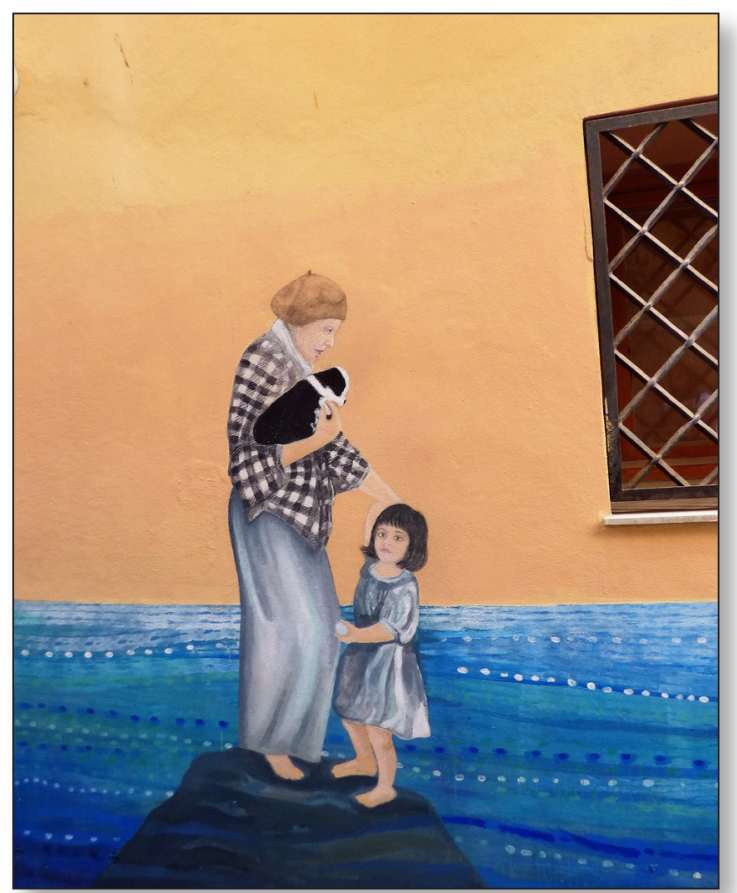

Fig. 2. El paso del tiempo.

IMAGO, NÚM. 10, 2018, 99-124 


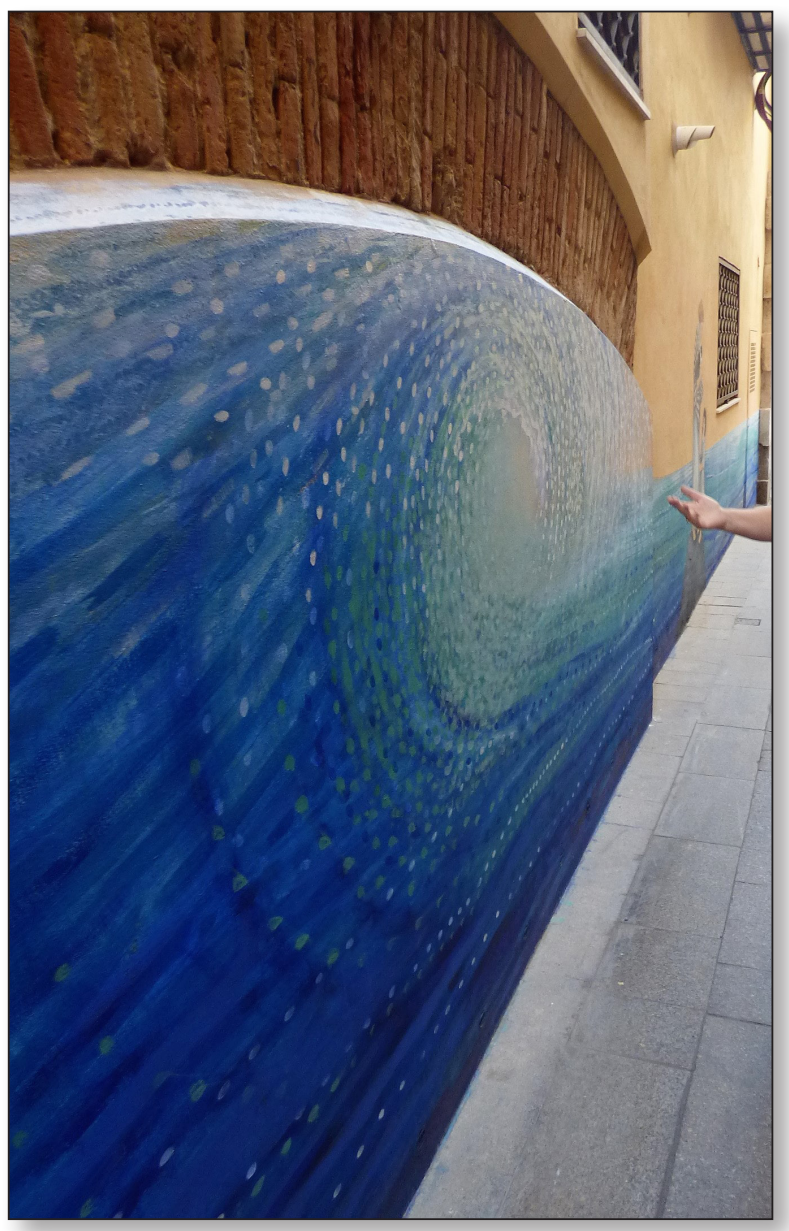

Fig. 3. Tsunami.

Vicent Zuriaga: ${ }^{2}$ ¿Cómo interpretar los perfiles, los rostros que aparecen en muchos de tus trabajos, en olas o en árboles?

V C: Representan la aventura y el espíritu de las personas que son uno con la naturaleza, y en ella dejan su impronta. Aquí he pintado un tsunami [fig. 3] que nos recuerda lo pequeño e insignificante que es el ser humano cuando la naturaleza manifiesta su presencia abruptamente; y esto son huellas blancas pues he invitado a la gente que pasaba mientras yo pintaba a dejar su huella. Esta ola gigantesca puede ser interpretada de varias maneras: como un viaje interior a la potencia y fuerza de la naturaleza con las consecuencias dramáticas que podemos imaginar si somos atrapados y arrastrados por ella; o puede aludir a esas olas conocidas como olas mecánicas que trasladan consigo una gran energía y que dependiendo del viento propiciarán el deleite de los surfistas y por ello podemos considerarlas como elemento de diversión.

2. Conservador de Museo de Arte Contemporáneo de Vilafamés MACVAC. Investigador del Grupo Apes de la Universitat de València e investigador del Grupo Humanidades Digitales de la Universidad Católica de Valencia. 


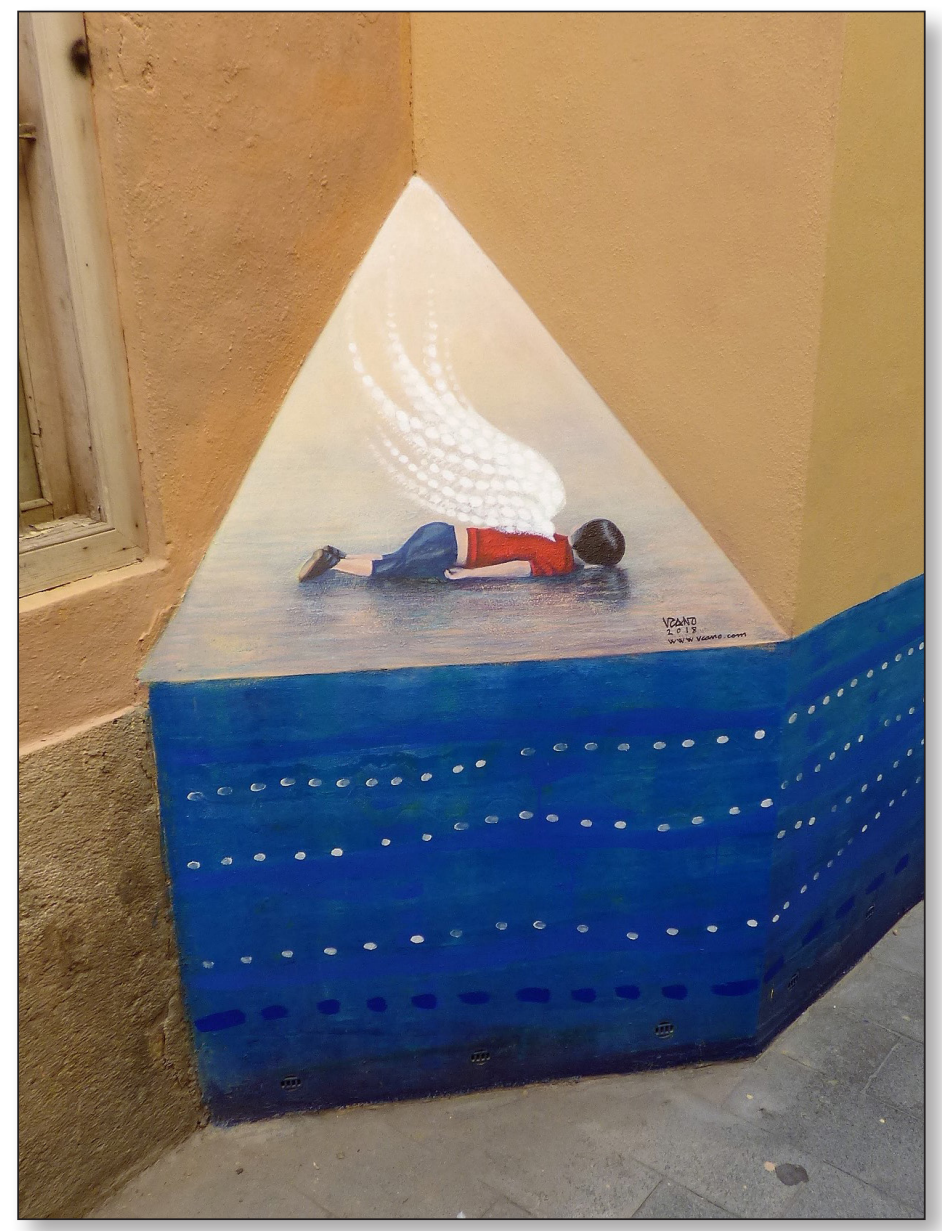

Fig. 4. El ángel del Mediterráneo.

Ahora os voy a mostrar el mural de la esquina [fig. 4] en el que he conectado todo lo que os he comentado con el drama del Mediterráneo, el de los refugiados cuya única alternativa es la huida por el mar. En él rindo homenaje a Aylan Kurdi, el niño de tres años que murió junto a su madre y su hermano Galip de cinco en una isla griega huyendo de la guerra de Siria. Antes hemos visto el amor de madre. Aquí he contrapuesto la simbología de la muerte a la simbología de la nueva vida con las alas. Para pintar las alas (que también se pueden interpretar como una paloma) que elevan el espíritu, he utilizado huellas blancas, huellas que representan a cada una de las personas fallecidas en el intento de cruzar el mar en busca de una vida mejor, del paraíso utópico. Esas alas simbolizan el drama individual y colectivo de las almas de todos los que han perdido la vida en el Mediterráneo. 


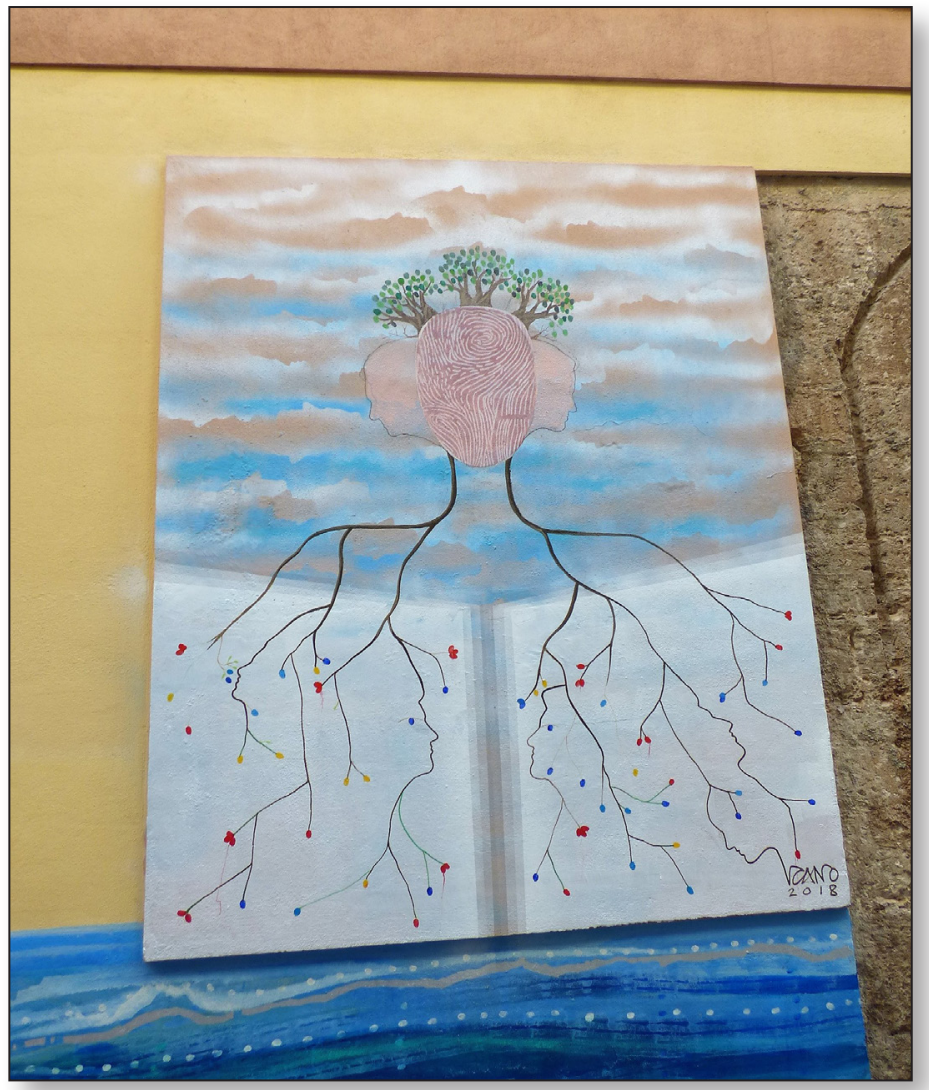

Fig. 5. El dios de las pequeñas cosas.

V Z: Es un tema atemporal, el drama del ser humano, y no podemos mirar a otra parte como denunció el Papa Francisco en Lampedusa. ${ }^{3}$

V C: He convertido a Aylan en el ángel del Mediterráneo.

Y este mural [fig. 5] es un trabajo a partir de la novela El dios de las pequeñas cosas de Arundhati Roy. He creado un personaje donde la huella representa el ser humano que es al mismo tiempo femenino y masculino, y a la vez relacionado con la naturaleza. En la India el dios Shiva es el dios de la naturaleza; controla los elementos (fuego, agua, aire, tierra) y como ellos puede ser creador, destructor y regenerador. Esa misma deidad nos habla también del cuidado de la naturaleza, y en ese sentido está en sintonía con lo que yo trabajo. Como veis, las raíces se convierten en perfiles de personas que van en busca del agua como fuente de vida. El agua se ha convertido en un elemento en el que la vida y la muerte están entrelazadas.

3. «¿Quién de nosotros ha llorado por este hecho y por hechos como éste? ¿Quién ha llorado por la muerte de estos hermanos y hermanas? ¿Quién ha llorado por estas personas que estaban en la barca? ¿Por las jóvenes mamás que llevaban a sus niños? ¿Por estos hombres que deseaban algo para sostener a sus propias familias? Somos una sociedad que ha olvidado la experiencia del llorar, del "padecer con»: ¡la globalización de la indiferencia nos ha quitado la capacidad de llorar!», <https://www.revistaecclesia.com/homilia-del-papa-francisco-enlampedusa/> 


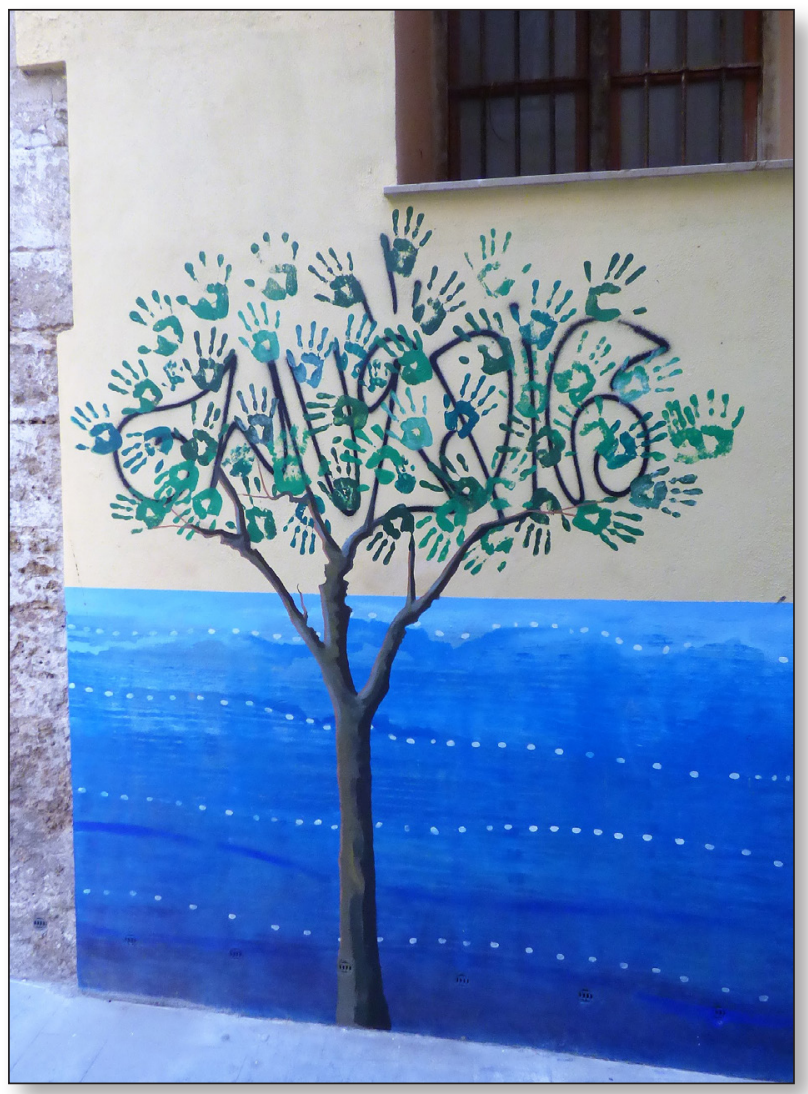

Fig. 6. Aprender a convivir.

V Z: Resulta curiosa la integración de una firma grafiti en este otro mural.

V C: Este trabajo [fig. 6] es una apuesta por la convivencia, por respetar y que te respeten. Realmente lo que sucedió es que destrozaron la pintura de la fachada de mi casa con un grafiti tipo firma gigante. Hemos de aprender a convivir; así que en lugar de borrarla, tomé la firma como base y he pintado un árbol con las huellas de las manos de muchas personas. La gente del barrio y los paseantes anónimos fueron invitados a participar en el proyecto. He dibujado un tronco y he creado un árbol en el que conviven el mural con el grafiti - al lado voy a hacer otro árbol, aquí donde vemos firmas, frases, dibujos [...] Puesto que ya había dejado uno su impronta, pues ahora animo a todos los que quieran participar desde el respeto. Esta obra poco a poco va tomando forma: es como una mano abierta en la que estoy integrando todos los nombres, los corazones, los mensajes o los dibujos que otros han dejado a su paso.

Este proyecto tiene que ver con la huella, el dejar huella, y de alguna manera es una reflexión sobre la vida, porque todos dejamos huella, bien sea positiva o negativa. Es una manera de intervenir. Aquí vemos firmas de grafiteros que han respetado el proyecto; están integradas y por ello he pintado ramas que marcan su espacio. Junto a ellos podemos ver la intervención del bibliófilo Rafael Solaz (Presidente de la Sociedad Bibliográfica Valenciana Jerónima Galès) que en su firma introduce el perfil de la Valencia antigua con el Miguelete, la Catedral, las Torres de Serranos.

IMAGO, NÚM. 10, 2018, 99-124 


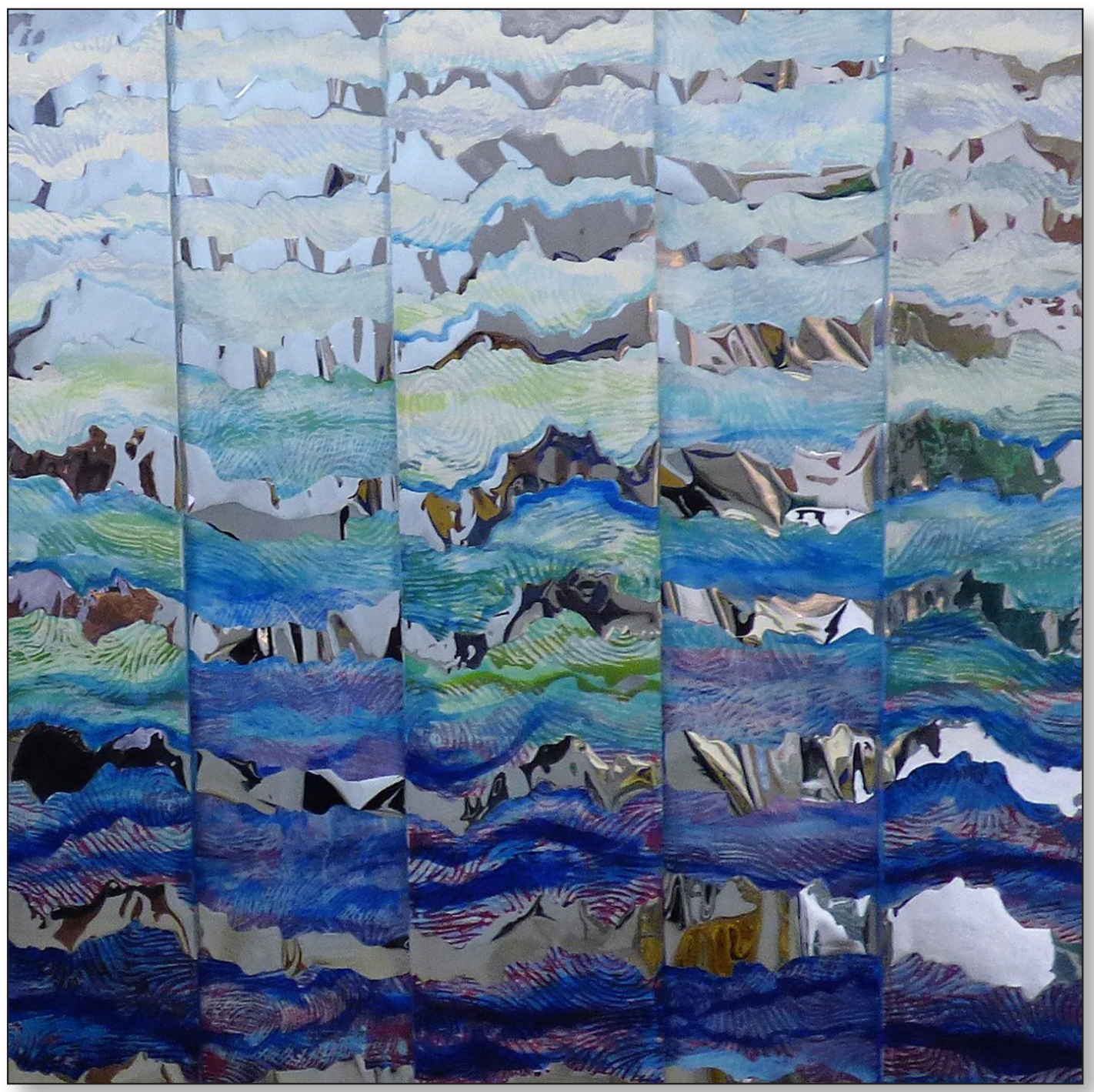

Fig. 7. Ecos del Mediterráneo.

Ya conocéis mi faceta de artista urbana y ahora pasamos al interior de mi estudio. Este es un cuadro de 2016 titulado Ecos del Mediterráneo [fig. 7] que identifica el concepto de lo que es mi pintura: el agua como tema, los perfiles, las degradaciones de azules y verdes; esa sensación de brillos que te da el agua, y al mismo tiempo el agua como espejo en el que nos miramos. Seguramente sería el primer espejo -ahí nace el mito de Narciso. De esta forma vosotros como espectadores estáis dentro del cuadro, y además de estar dentro del cuadro estáis en movimiento, en tránsito, es decir, dentro del cuadro con la sintonía y el movimiento que te da el agua. 


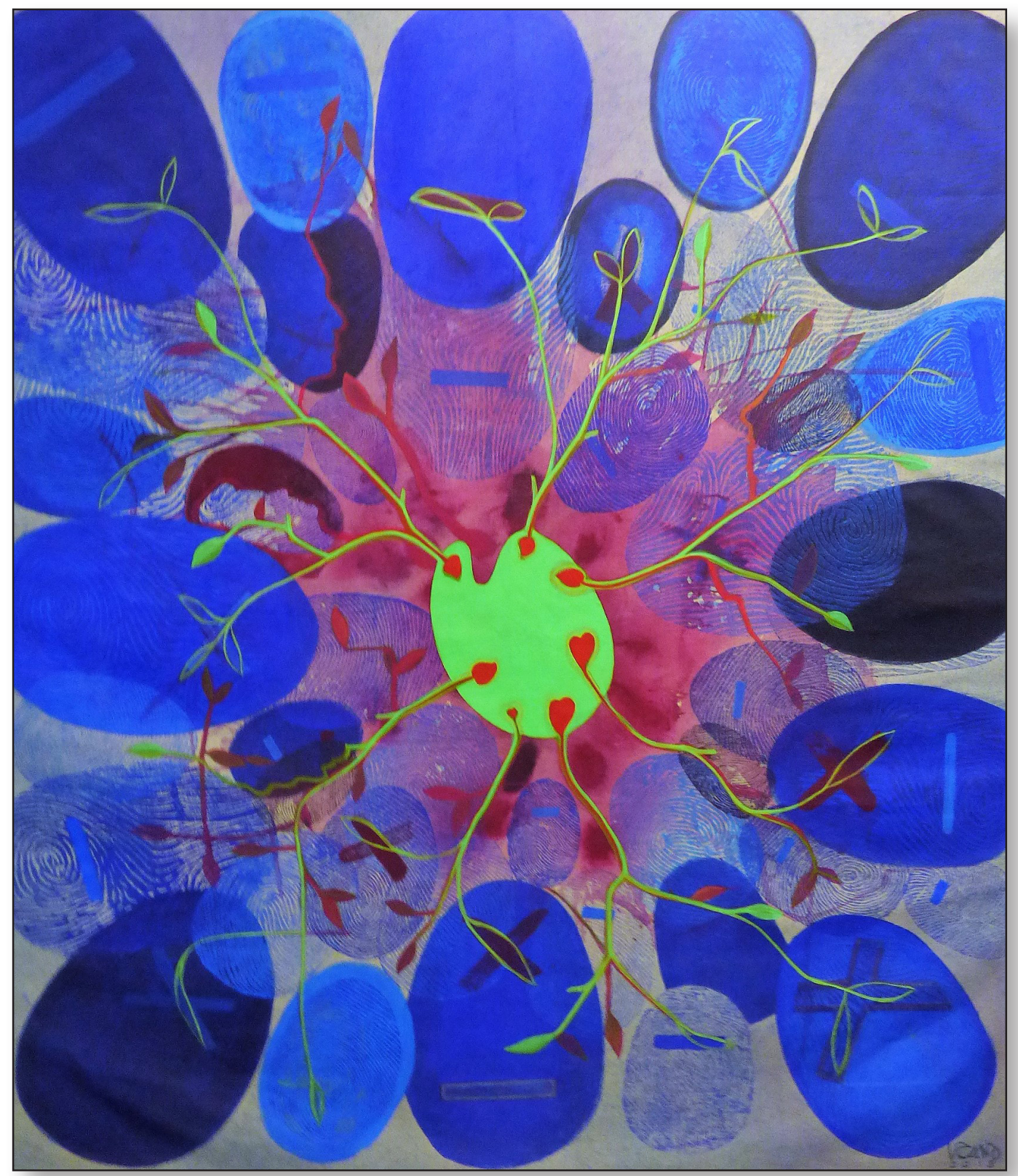

Fig. 8. Paleta de corazones.

N A: Paleta de corazones (2013) [fig. 8] fue seleccionada por Isabel Coixet y la podemos ver durante unos segundos en Spain in a Day (2016). ¿Qué nos puedes comentar sobre esta obra?

V C: Es un cuadro que habla de la energía, del color, también de la pasión, de la cultura [...] del arte que al fin y al cabo nos mueve porque nos emociona, nos hace latir el corazón. En el centro hay una paleta y en lugar de poner colores, he puesto corazones que de alguna manera son los motores que propulsan la energía que late en las personas.

IMAGO, NÚM. 10, 2018, 99-124 


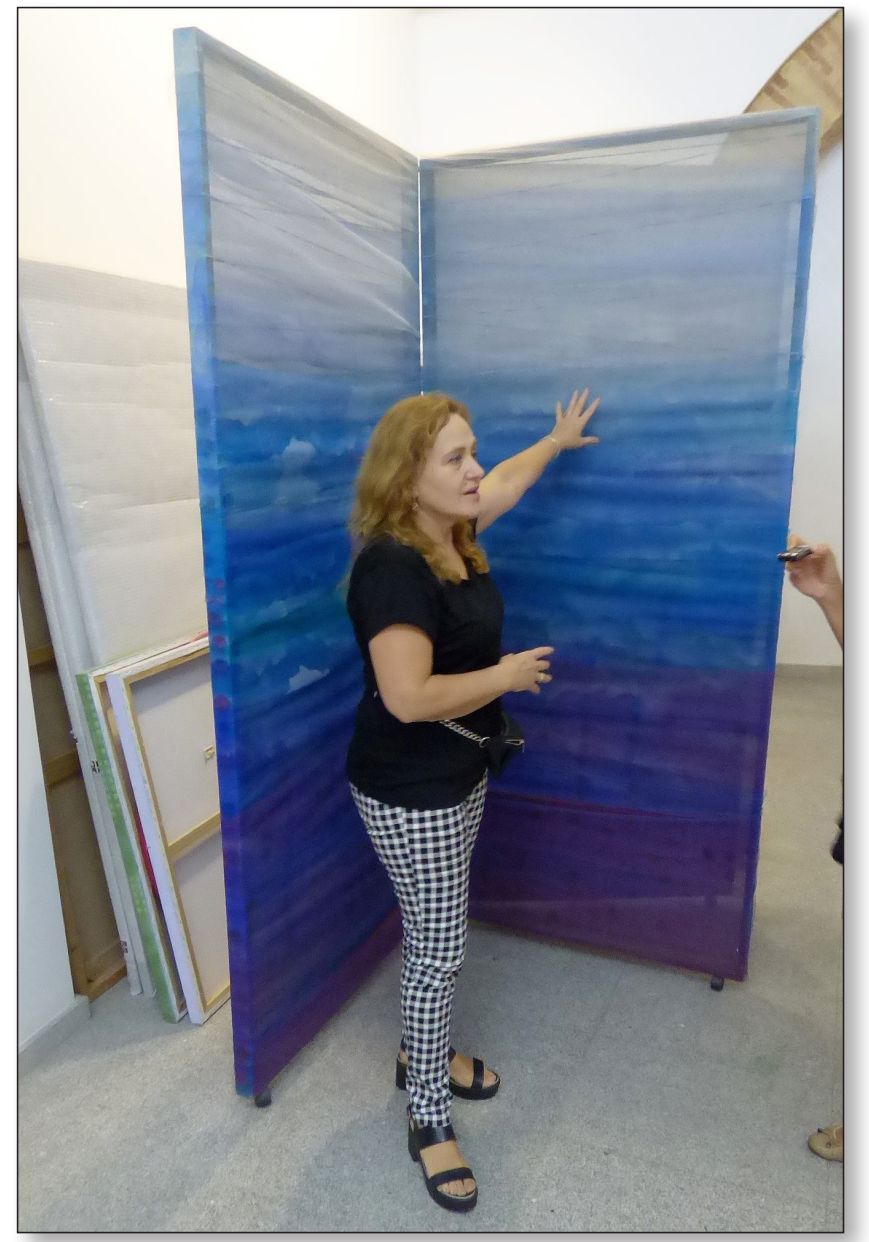

Fig. 9. Libro artístico.

V Z: En el patio nos encontramos con distintas instalaciones que tienen como objeto de representación los libros.

V C: Libros llevo haciendo toda mi vida. Me he de remontar al año 1981 pues hice mi primer libro durante mi estancia en la Academia Española de Bellas Artes en Roma como pensionada. Iba a la calcografía nacional para hacer grabados y pintura. Hice libros artísticos para registrar cosas que hacía y me sucedían. Estos trabajos se plasmaron en una exposición del periódico Il Manifesto donde una de las obras que presenté fue un libro cosido con intervenciones de máquinas, de cosidos, de pegados, de gofrados. Estos libros artísticos de grandes dimensiones son de 1999 [fig. 9], año en el que también presenté un libro blanco titulado Metros de creatividad en el que invitaba a la gente a que escribiera. Los libros son como el espíritu de las personas. Son como los pensamientos. Te permiten volar, viajar, y de alguna forma están ahí para transmitir emociones, sentir las palabras, el espacio que convive con el pensamiento. Aunque las personas no estén, quedan sus escritos. Esto es lo que representan estos libros suspendidos en el aire, en continuo movimiento [fig. 10]. 

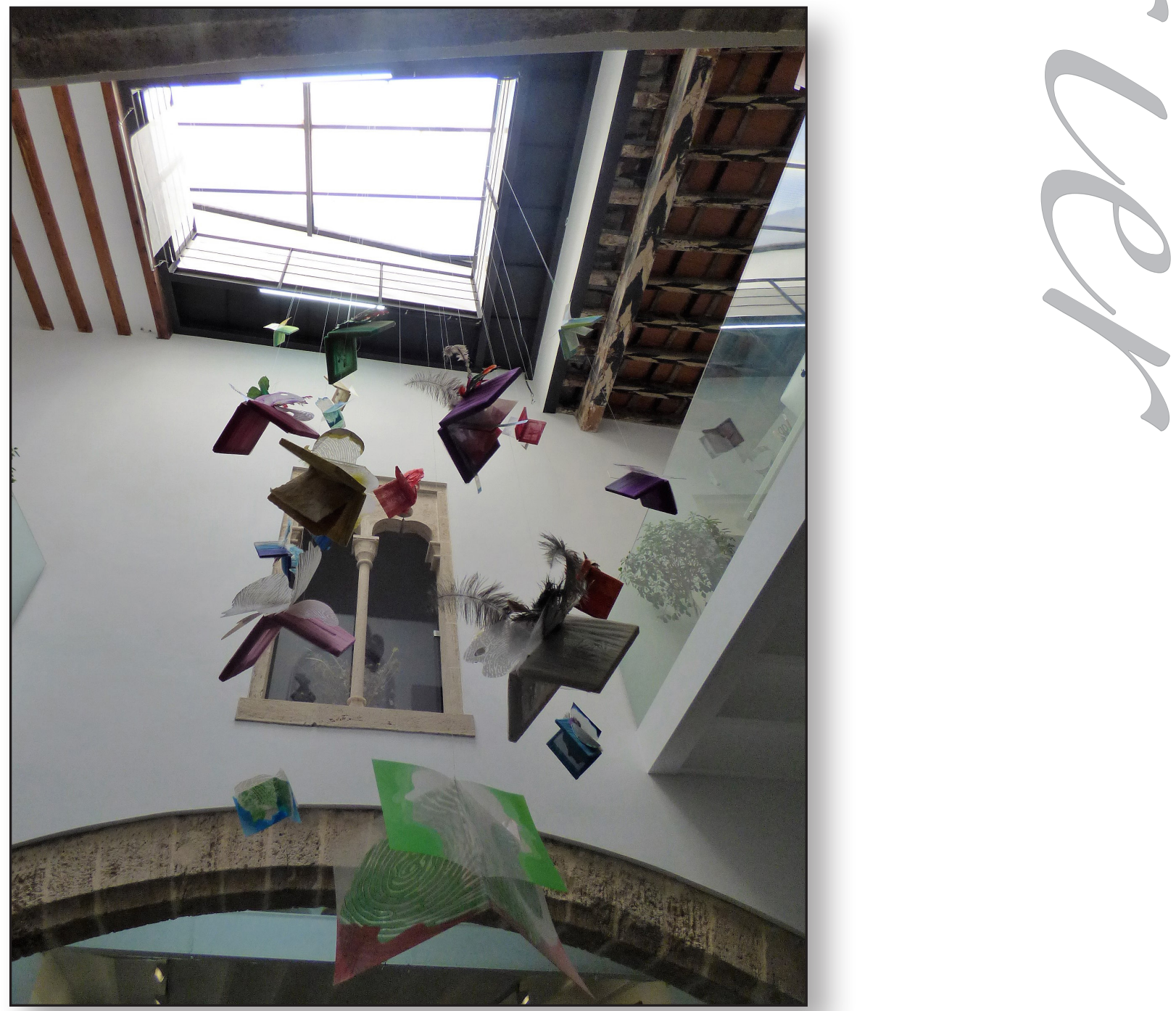

Fig. 10. Libros voladores.

N A: ¿Desde cuándo trabajas la idea de los libros voladores?

V C: En 2010 volví con una exposición a la Academia Española de Bellas Artes de Roma. Un año antes recibí el encargo que coincidió con el terremoto de l'Aquila. La obra que presenté consistió en 200 libros voladores en homenaje a las 200 personas que habían muerto. La exposición tuvo lugar en cuatro salas. En el claustro y en el jardín instalé los libros voladores como los que veis aquí en el patio de mi estudio. Después de la exposición fui a l'Aquila y doné tres de ellos, mi homenaje al espíritu y energía de los que perdieron la vida.

En cada exposición de alguna manera los libros (los de gran tamaño, los voladores, etc.) siempre aparecen. Son parte fundamental de mi obra pues me permiten contar lo que no puedo pintar.

IMAGO, NÚM. 10, 2018, 99-124 


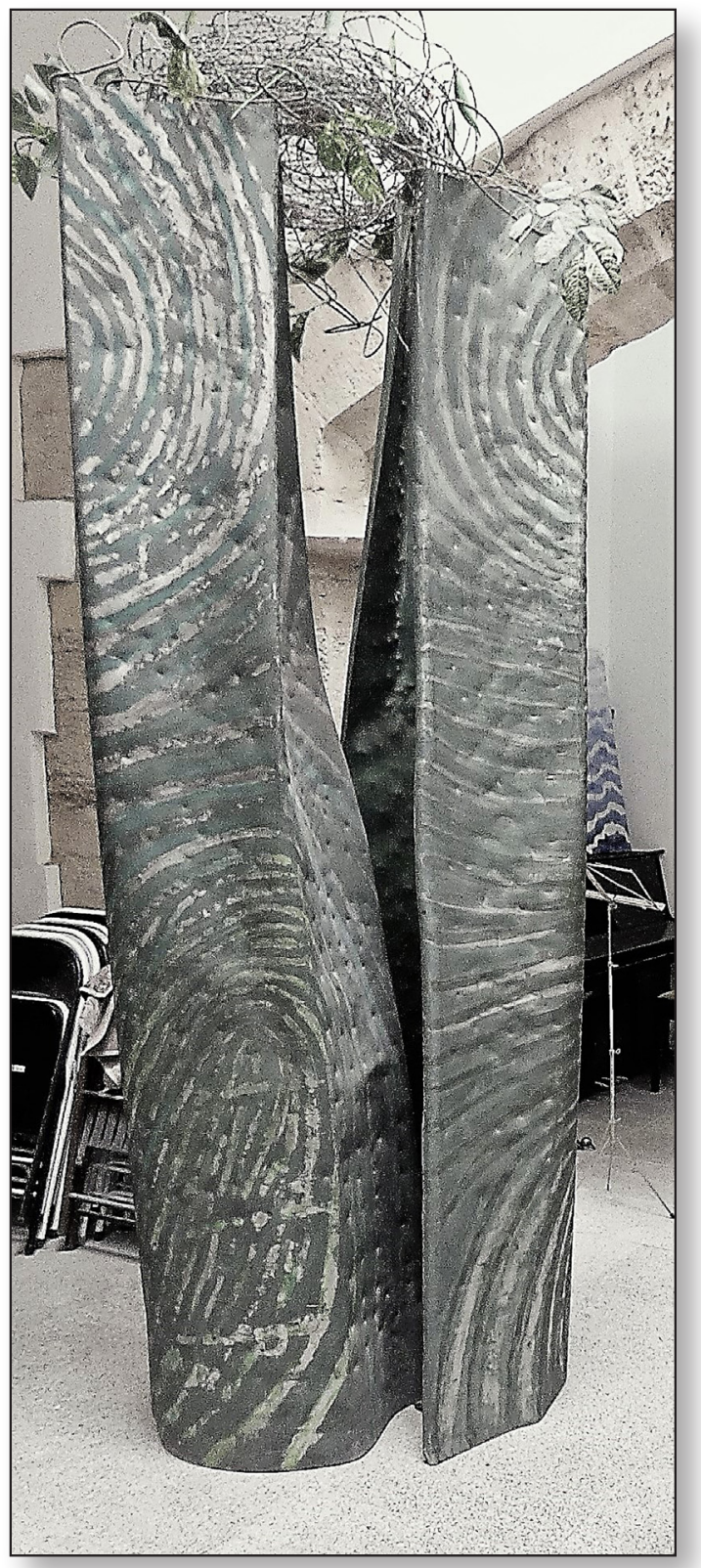

Fig. 11. Troncos con nido.

V Z: Los árboles son también una constante en tu obra.

V C: Esta escultura, Troncos con nido (2002-2015), son dos troncos monumentales que miden más de tres metros en aluminio pintado [fig. 11]. Podría haber pintado sobre una tela, pero he preferido el aluminio para tener una sensación diferente. La corteza de los troncos es como la piel de la naturaleza; la corteza de los árboles es como nuestra piel. Si no cuidamos los árboles y la naturaleza, no tendremos oxígeno para respirar. Conectamos de nuevo con el agua, la tierra, el fuego, la vegetación, pero haciendo uso de nuevas técnicas que permiten expresar, representar y trabajar aspectos como la luz como veremos más tarde en una obra que presenté en una exposición en el Palau de la Música de Valencia en 1999.

N A: ¿Hay influencia de la música en tu obra?

V C: Durante mi estancia en Roma como pensionada, conocí a Mauricio Furlani. Le encantó mi obra, a mí su música. Dediqué toda una serie de pinturas y grabados a sus composiciones.

Hay un cuadro seleccionado para el Festival de Mostra Viva del Mediterrani 2018 en donde se fusiona el audiovisual, la pintura y la música. Planteé un proyecto Mensaje entre multitudes (2010). Es un tríptico que a su vez es una videoinstalación, compuesta por multitud de huellas y perfiles blanco sobre blanco, prácticamente todo en tonos blancos. En el centro aparece un óvalo gigante que es como un personaje, una huella, un poco como la esfera del cosmos, una mandorla, un óvalo en forma de cabeza sobre el que proyecto imágenes de personas que he ido capturando durante años preguntándoles qué piensan del mundo, qué dirían a la vida, qué dirían a los demás. Sus emociones, esas cosas que han compartido conmigo, las he hecho en pintura y Emilio Calandín lo ha transformado en música (El sonido de la huella) y Luís Fernández lo interpreta con el clarinete. Es muy bonito porque hemos interpretado qué es música, video y pintura, al tiempo que integramos las voces de la gente -personas mayores, profesores, catedráticos, críticos de arte, emigrantes, etc. 


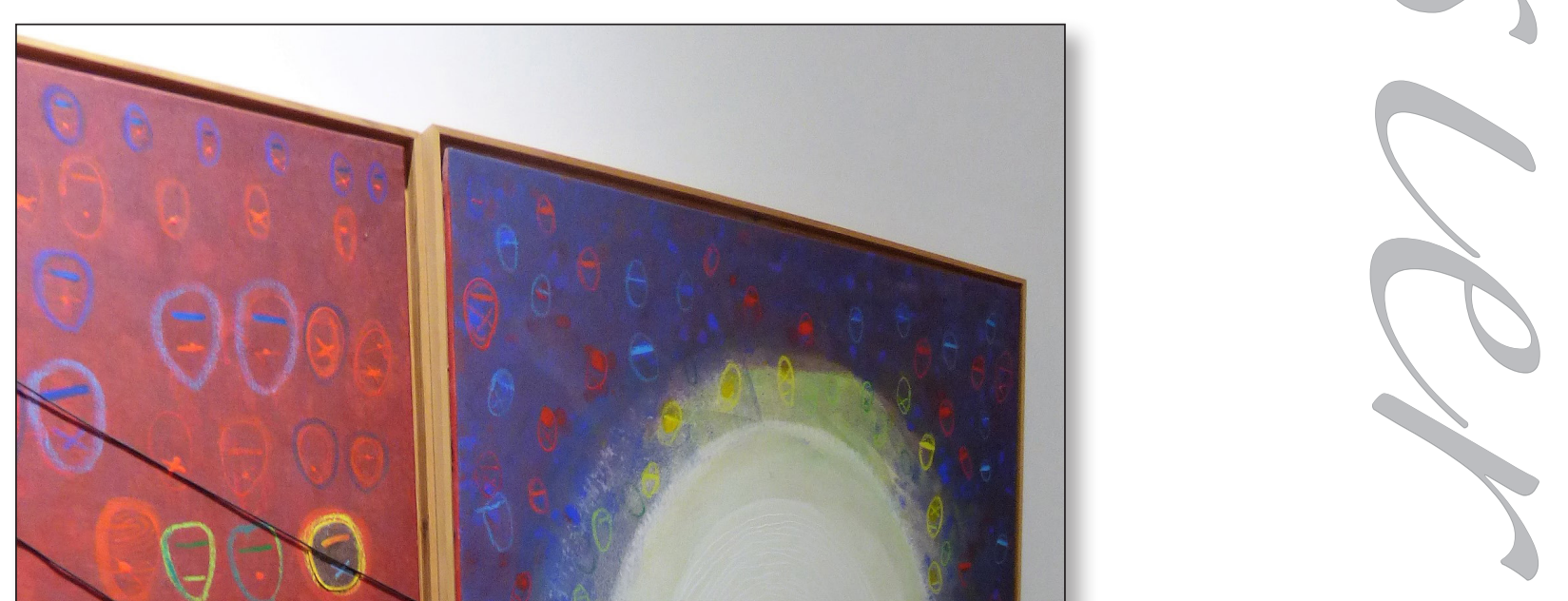

V Z: Esta obra [fig. 12] me evoca el omphalós de Delfos que era el ombligo del mundo donde el dios Apolo con su luz se manifestaba a las pitonisas. En ese sentido, y no sé si de una manera casual, pero en él aflora tu formación clásica y cristiana; en cierta medida bebes del mundo clásico y cristiano, de esa relación, a través de ese óvalo de luz que evoca la luz del Panteón de Agripa, o la mandorla mística, desde donde la divinidad le habla al hombre: Ego sum lux mundi... Es curioso que esa tradición de la que bebes de manera consciente o inconsciente se explica desde el principio de disyunción del arte cristiano, y cómo éste bebe de las fuentes clásicas.

IMAGO, NÚM. 10, 2018, 99-124 


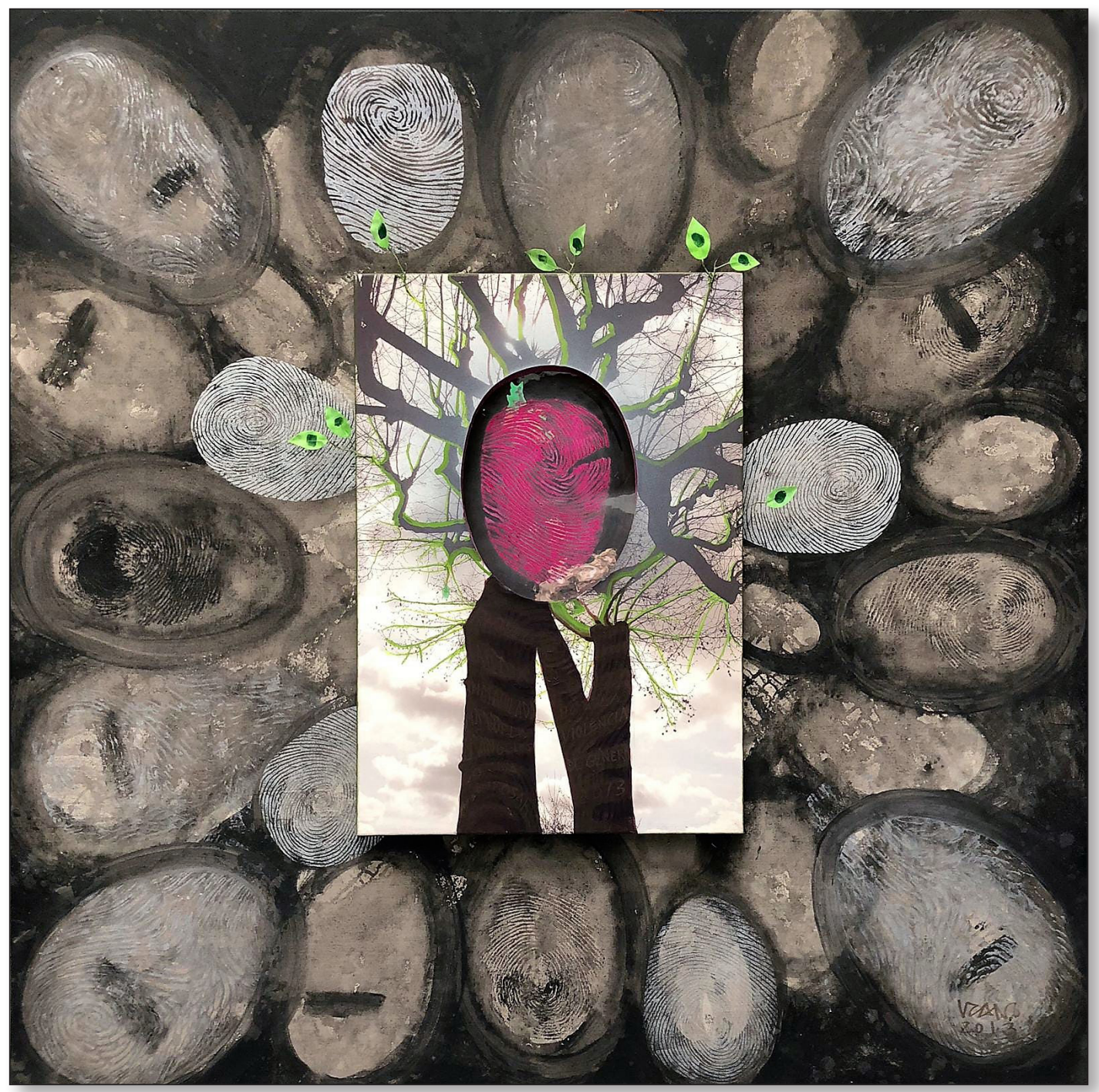

Fig. 13. No a la violencia de género.

V C: En este caso es una mandorla contemporánea gracias a las nuevas tecnologías porque las técnicas al final son las que te permiten poder conectar unas cosas con otras. Un óvalo que es una huella blanca, iluminada por la luz, pero cuando proyectas a la persona y su voz, se convierte en un óvalo blanco sobre blanco sobre el que a través de la música y la palabra hablan las personas.

El óvalo está también muy presente en una de mis obras de 2013 titulada No a la violencia de género [fig. 13], expresión de mi compromiso como mujer y, más importante, mi compromiso como ser humano. Aquí tenemos un omphalós que conecta con la naturaleza. Es un cuadro complejo porque aunque están escritos los nombres de mujeres asesinadas ese año, no los puedes ver. Para visibilizar sus nombres necesitamos ver el cuadro en la oscuridad. La pintura de los nombres es fluorescente de tal manera que tú 
no tienes por qué ver lo que yo no quiero que veas; solo te lo muestro si quiero. Forma parte de los secretos de mis cuadros. El tronco del árbol tiene forma de $\mathrm{N}[\mathrm{o}]$; hay huellas y los anillos representan las texturas de la piel del árbol. Este cuadro se expuso en el Centro del Carmen. El día de la inauguración invité a los familiares de las personas asesinadas a dejar sus huellas sobre pequeños brotes de hojas verdes. Pero hay algo que es crucial en esta obra, es clave para entender su significación. El óvalo es un espejo en el que todas y todos nos vemos reflejados, un omphalós que nos descubre un mensaje: «También te puede pasar a ti». Una invitación para que de alguna forma las personas se miren al espejo e imaginen la realidad de esas mujeres asesinadas. El uso del color también es importante; como podéis ver dominan los grises. Me inspiré en un cuadro de Piero de la Francesca que vi en Urbino titulado Flagelación de Cristo. El mío es un cuadro que representa el luto, la muerte de un familiar, tenemos detrás la metáfora de una historia paralela que quiere expresar algo diferente que va más allá de la muerte. Lo expreso con color matizado con grises. Hice una cuatricromía donde desglosé los colores y puse el rojo en relación a distintos grises y aprendí muchísimo del tratamiento del color estudiando y analizando el cuadro de Piero de la Francesca. Para expresar ese dolor, esa tristeza, utilizo los ojos y huellas que están como tapadas con elementos que te inmovilizan en una mirada oscura. Por ese motivo he puesto en el centro un espejo donde puedes ver todo el color de cada uno: el color lo pone la espectadora, el espectador.

Es un cuadro inspirado por el arte clásico, pero al mismo tiempo es arte contemporáneo donde dejas ver y transmitir. Te puedes poner delante del espejo del óvalo que está hecho con un plástico especial que existe ahora y no existía hace diez años, reflejarte en el plástico que actúa como espejo, meterte dentro y estar dentro de la obra con tu color, con tu mirada, con tu color de piel, tu color de pelo, y de alguna manera como si eso todo fuera la cabeza de la naturaleza envuelto y rodeado de ramas y de troncos para adornar e interrelacionarse con la naturaleza. De hecho nosotros nos adornamos mucho; nos colocamos cosas en el cabello cuando vamos a una fiesta, por ejemplo. Me vienen a la mente las bacanales en la tradición clásica, todo adornado con flores y plantas. A mí me interesa el arte contemporáneo porque deseo pintar las huellas de la gente que conozco, que están y me aportan. No necesito reproducir la sonrisa de la Gioconda, ni a Piero de la Francesca, ni a Piranesi. Tengo que ser Victoria Cano. Como artista contemporánea, como pintora, he de hacer mis propias lecturas, compartir mis vivencias: cómo me afecta la situación que se vive en el Mediterráneo, cómo lo veo y cómo lo interpreto a través del color, de las formas, de las líneas, de las texturas, de las estructuras y micro-estructuras que encierran uno o varios mensajes para el deleite de los que les guste el arte.

$\mathrm{N}$ A: Siempre tienes en cuenta al espectador a quien invitas a mirarse en ese juego de espejos, a dejar su huella o su firma, fotografías su perfil. Pasarán los años y nuevos rostros se asomarán y se reflejarán en tu obra.

V C: Sí, y mi obra les hablará de nuevo, les advertirá de nuevo pues es atemporal.

V Z: Por mi formación, la lectura de tu obra se asocia con el subconsciente...

V C: Podemos decir que al contemplar un cuadro uno ve lo que sabe. Hay personas a las que una obra no les dice nada, pasan y lo único que ven es un agujero. Pero las que conocen, o tienen ciertas inquietudes, ven y conectan. Creo que hay conexión a distintos niveles en el universo. Hay personas que ven cosas distintas; eso significa que están conectados a distintos niveles. Esas conexiones entre distintos campos o materias son las que permiten que se produzca una conexión espiritual, conceptual, intelectual, emocional o física -en 
uno o en varios niveles- entre personas que nunca han hablado. Porque al fin y al cabo todo es energía. Cuando me preguntan: «¿Qué pintas?» Contesto: «Yo pinto la energía. Es mi compañera de trabajo.»

V Z: Lo que tú llamas energía y manifiestas a través de la luz, los griegos lo llamaban Apolo y los cristianos le llaman Cristo...

V C: Es que Dios es energía. Si existe algo, es la energía que lo mueve todo.

$\mathrm{N}$ A: Aquí podemos ver dos libros de gran formato. Uno resulta muy poético, en el otro las telas, el rojo y el negro apunta una tragedia. ¿Qué nos puedes comentar sobre ellos?

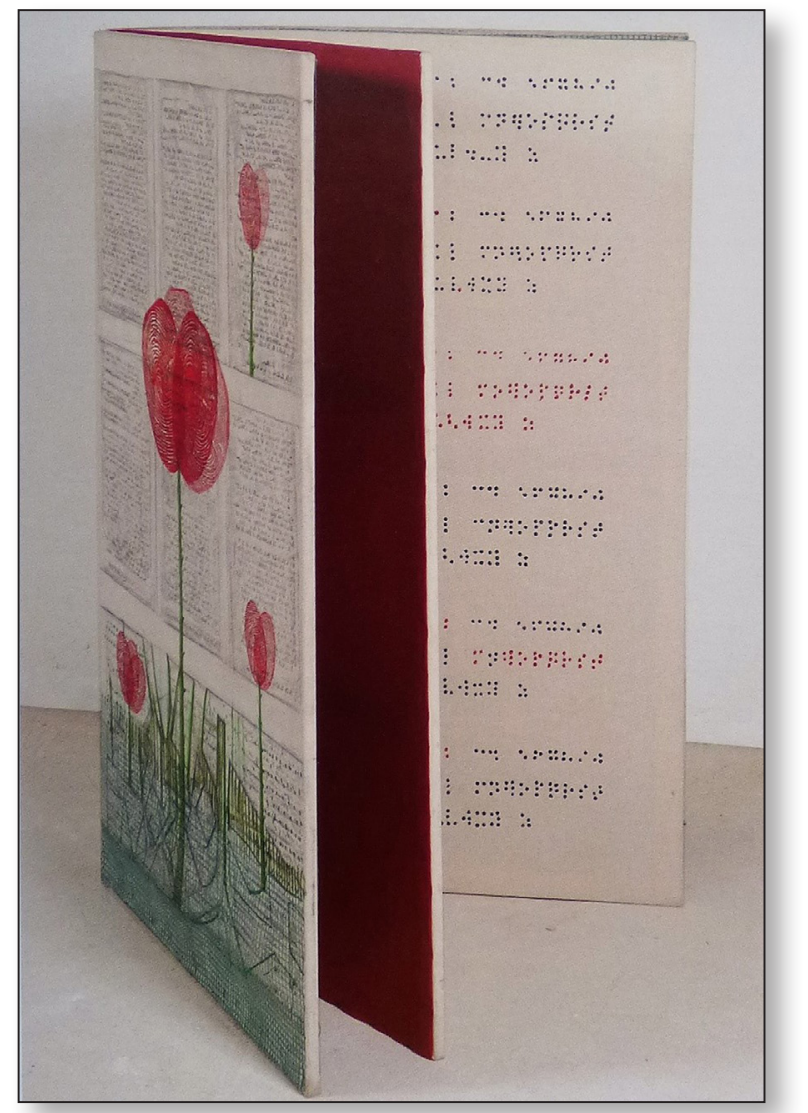

Fig. 14. Libro para el tacto.

V C: Este trabajo es Libro para el tacto (2005) y está dedicado a los que no pueden ver. [fig. 14]. En su interior está el alfabeto braille; deslizamos los dedos y están la a, la b, la c, etc. En la portada y contraportada del libro vemos un frottage con grafito del braille auténtico de las placas en las que se explica cómo se construyó la Catedral de Valencia y que se encuentran en la Plaza de la Reina. Es una manera de decir que las cosas a veces se aprenden con dolor, que la belleza tiene también ese componente simbólico como estas rosas de la tapa que tienen espinas que pinchan. 


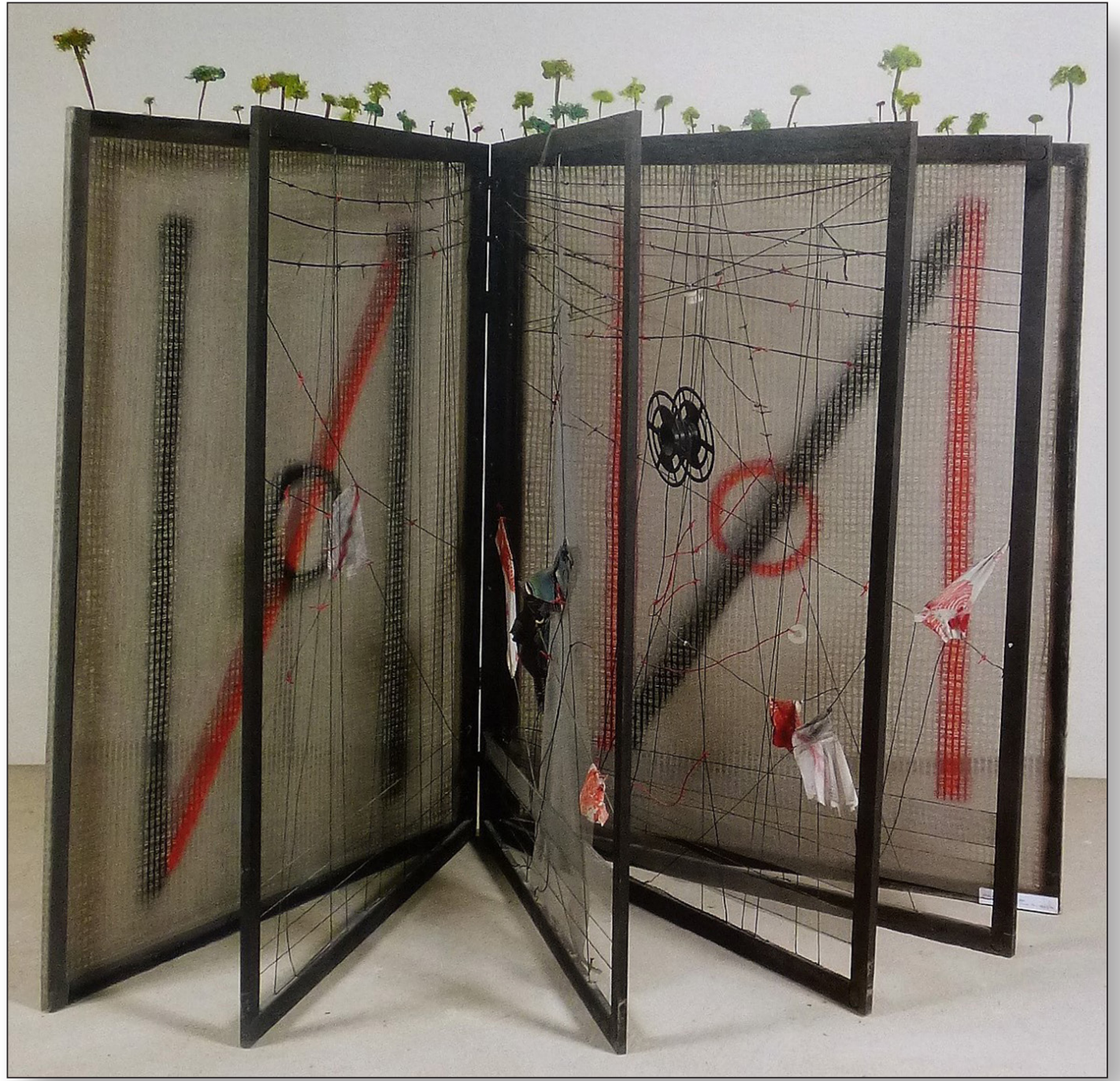

Fig. 15. Estallido entre páginas.

Esta otra es una instalación que hice tras el $11 \mathrm{M}$. Es un libro recordatorio que titulé Estallido entre páginas (2004) [fig. 15]. Cuando estaba expuesto hubo otro atentado y por ese motivo le pusimos este crespón. Los troncos de estos arbolitos son clavos que aparecieron aquí en la casa cuando nos mudamos a vivir aquí; son como los clavos de Cristo, pero les he puesto musgo y les he dado nueva vida, un renacer. Son restos del pasado a los que he dado un nuevo impulso. Es también una obra atemporal pues siempre hay un estallido, un atentado aquí, allá. Lo que sugiere mi obra es la atención que debemos tener, debemos estar en constante alerta. Utilizo tela pintada, alambre, cables para hablar de la vida, para representar el estallido, y en negro y rojo dibujo la palabra NO que a su vez es un 11. Según la mirada, esos niveles a los que aludía antes, habrá espectadores que conecten con el horror de las guerras, los campos de concentración, la muerte de inocentes, etc. 


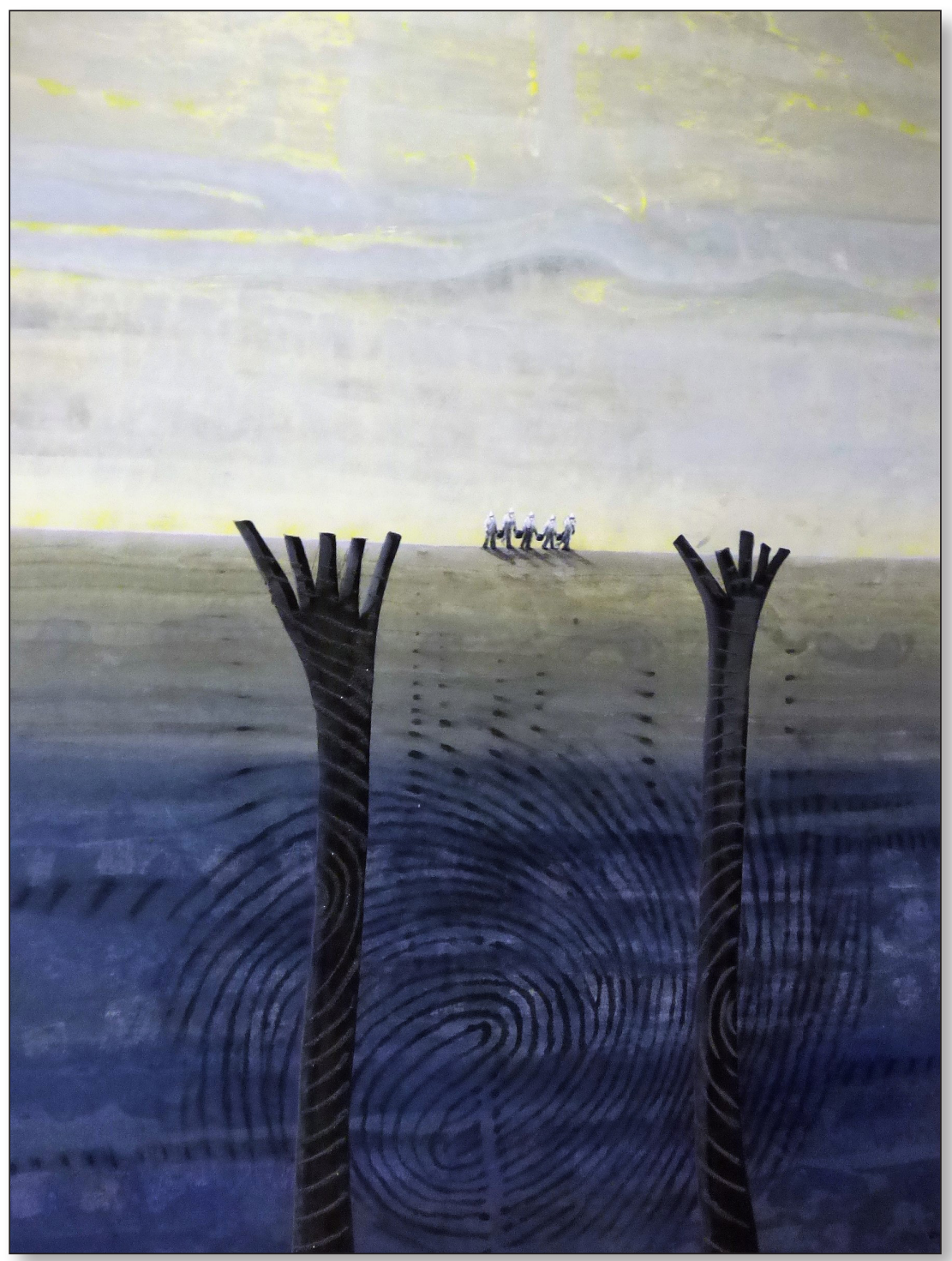

Fig. 16. Desastre del Prestige.

Vamos a pasar a la sala donde veréis cuadros de gran formato. Uno trata sobre el desastre del Prestige [fig. 16]. Es sobre la huella, nuestro impacto, esa mancha que somos capaces de dejar en la naturaleza. Luego nos vemos en el filo de la navaja, en el límite del horizonte, para poder quitar lo que hemos sido capaces de hacer. Aquí vemos unos troncos que son como unas manos de auxilio, manos cortadas que simbolizan nuestra pequeñez pues no damos abasto para poder limpiar y quitar todo el daño que hacemos al medioambiente. Ahora está el tema del plástico que se tira al mar. En fin, cuando no es una cosa es otra; es un ciclo y lo que yo hago es sensibilizar de alguna manera a través de la pintura sobre temas medioambientales o sobre la Guerra de Iraq o sobre lo que dejamos después de la guerra. 


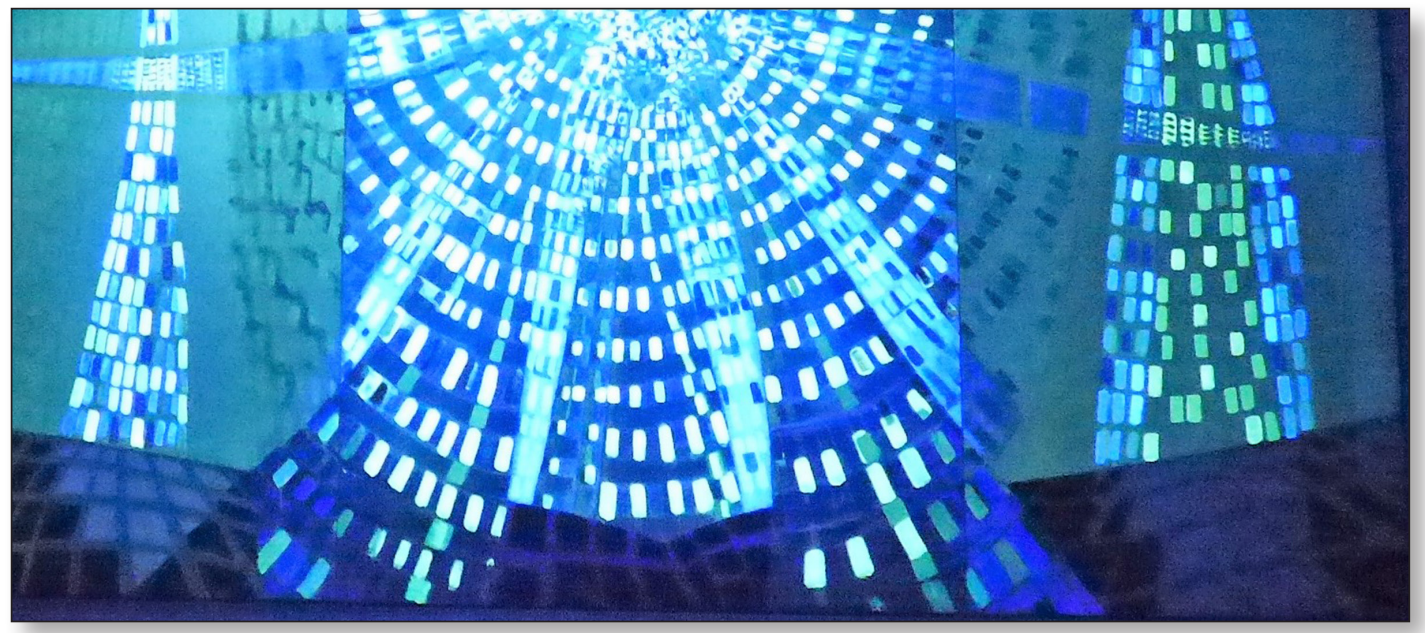

Fig. 17. Tríptico de diálogos entre el día y la noche.

N A: Otras obras de gran formato son Mensaje entre multitudes (2010) y Los álamos del jardín (2010). La primera de estas video-instalaciones la podemos ver en internet. ${ }^{4}$ Sobre la segunda nos has comentado que has trabajado el espacio y el tiempo, la sensación de la energía en transformación, has conseguido que el paisaje esté vivo, en movimiento. ¿Podrías mostrarnos cómo puede cambiar un cuadro dependiendo de la luz que se aplique y de las pinturas que se utilicen?

V C: Por supuesto. Aquí tenemos Tríptico de diálogos entre el día y la noche [fig. 17], obra que habla de la energía, de la luz, de la luna, incluso de la energía eléctrica. Estaba pintando este cuadro cuando sucedió el atentado terrorista contra las Torres Gemelas (2001). El cuadro está planteado desde la búsqueda de la luz; aquí vemos una especie de troncos de árboles que terminan en manos que de alguna forma buscan la luz, la de la luna, la del sol. Ahora voy a aplicar luz negra para poder ver la luz interna, ver la energía como la clorofila que atraviesa los trocos de los árboles. ¿Preparados? [...] ¿Qué os ha parecido?

N A: Espectacular. Al dejar la sala a oscuras y aplicar la luz negra, el cuadro cobra vida. Se aprecia con gran intensidad los colores (verdes, amarillos, azules, etc.). Nos descubre la belleza, es un canto a la esperanza. Pintura, arquitectura, naturaleza se entrelazan en lo que podría denominarse la catedral de la naturaleza. Por unos segundos nos olvidamos completamente que estamos ante un cuadro, entramos en una nueva dimensión. Belleza en estado puro que no quieres que se acabe.

V C: Es un tríptico que representa el contraste entre la energía natural y la energía creada por el hombre, que nos hace crear de nuevo la noche y el día pero de otra manera que los clásicos y los antiguos no podían hacer con velas. Entra la energía eléctrica que se mezcla con la energía de la clorofila de las plantas y se crea la energía de los propios colores. Fijaos cómo permanecen los fotones que al interactuar con la materia transfieren una cantidad fija de energía. La temperatura está ahí pues cuando la pintura del lienzo recibe luz, la absorbe. Hay un tipo de pintura que absorbe la luz como la clorofila y entonces te da de nuevo esa energía, esa luz. Por lo tanto el cuadro está vivo, es un cuadro

4. «El poder de la huella. Mensaje entre multitudes», <https://vimeo.com/174692081>

IMAGO, NÚM. I0, 2018, 99-I 24 
vivo. Aunque he compartido datos, me gustaría que al verlo pudierais sentirlo, emocionaros, me encantaría poder seduciros con él a través del color, de la luz, e invitaros a experimentar la conexión espiritual y física con la materia.

N A: Tras este espectáculo visual y haber experimentado de primera mano lo que significa que un cuadro esté vivo, tenemos otra pregunta. Manuela Ledesma en un escrito titulado La solución está en el laberinto (2006) comenta que eres heredera del expresionismo abstracto que surgió en Nueva York tras la Segunda Guerra Mundial y que quizá estés más cerca de Rothko que de Pollock.

V C: Disfruto trabajando con lienzos de gran tamaño y mientras pueda, lo haré. En cuanto a Rothko, sus cuadros tenían una energía tremenda, pero pintaba puertas, ventanas, que te van introduciendo en espacios; pintaba desde la desesperanza. Yo trabajo la energía, la materia, el ser humano, la naturaleza... todo desde la esperanza. Mi obra es positiva, como un árbol cuya energía es la fotosíntesis. Utilizo pintura fosforescente y fluorescente. Trabajo la luz que es energía, las emociones que me producen las cosas que suceden y busco siempre la parte positiva. Por otra parte, no renuncio a la denuncia, a poner el dedo en la llaga de lo que aflige al ser humano: la violencia, las tragedias, no son nada agradables; mis obras son denuncias para que no se vuelva a repetir. Todo lo que he pintado sobre el Mediterráneo son en parte denuncia. No pinto solo para deleite, pinto conectada con las fuerzas de la naturaleza, sobre lo que son capaces de hacer -a ti y al mundo entero.

V Z: Tu pintura tiene mucho de conceptismo del barroco, juegos de ingenio y agudeza, metáforas...

V C: Intento ser aguda; mis cuadros exigen contemplación y tiempo. Estar una tarde contemplando uno de mis cuadros es como leer un libro o ver una película. Mi pintura se decanta por presentar multitud de mensajes.

V Z: ¿Podemos utilizar la expresión «las capas de la cebolla» al hablar de tus obras?

V C: Para que los espectadores no se vean obligados a ver algo a primera vista, creo capas en mi trabajo. Sí, mis cuadros son como cebollas, siempre vas a descubrir cosas nuevas cada vez que los vengas a visitar. Además juego a crear sorpresa; me gusta el factor sorpresa, y que ciertos detalles no sean evidentes.

N A: Tu pintura tiene un componente poético... ¿cuál es tu viaje interior?

V C: Es algo que vivo cada día. Soy profesora y en clase pido a mis alumnos que hagan un viaje interior. Yo me lo aplico desde el autorretrato. No quiero que vean mis ojos azules, sino que lo importante es el viaje interior de mis sentimientos. Ese es realmente el recorrido interior que quiero que los demás vean. Además, ese concepto lo vemos en los libros voladores. Hay cosas que no se pueden pintar, pero hay cantidad de gente que deja huella de una manera maravillosa con poesía; como cuando escribiste tus poemas sobre mis cuadros que al leerlos me llegaron y me dio una sensación de escalofrío, de emoción. Me sorprende cómo a partir de la pintura alguien puede también escribir. Esa sensación es muy interesante, supone un viaje interior y al mismo tiempo es una manera de aprender, de ser tú misma la propia obra y que lo que sea el trabajo exterior sea reflejo del trabajo interior.

V Z: ¿Te consideras parte de una generación de artistas?

V C: La respuesta a esa pregunta la dejo en manos de los críticos. Lo único que puedo decir es que yo sí que me siento una artista de la época en la que vivimos. No soy una artista 
política, ni denuncio cosas por el hecho de estar en el candelero sino que trato temáticas a través del sentimiento y de la sensibilización. Me decanto por una manera más poética de decir las cosas sin molestar pero a veces puedo llegar a ser dura si es necesario.

N A: Has incorporado las nuevas tecnologías a tus obras ¿Cómo vives el abismo del equilibrio?

V C: Es muy sencillo, realmente yo pinto y me apoyo en profesionales, es decir, yo no lo hago todo. Es muy importante colaborar con profesionales de otras disciplinas pues es muy enriquecedor. He trabajado en diversos proyectos con el técnico informático Javier Campos con quien incorporé la tecnología de la "Realidad aumentada" así como otras tecnologías adicionales. Éstas te permiten hacer cosas, ver cosas que de otra manera no podrías hacer o ver. Con ellas hemos hecho volar los libros voladores, los hemos hecho cruzar una calle al igual que hicieron para la portada de su disco los componentes del mítico grupo británico los Beatles. Cuando un poeta comparte conmigo una poesía maravillosa, Javier y yo trabajamos en un vídeo que integramos gracias a las aplicaciones dentro de un cuadro, o en una orla, o en un libro volador, o en una postal. Si un compositor se inspira en uno de mis cuadros y lo transforma en notas, esas notas son números, números que equivalen a determinados ritmos de notas que al ser interpretadas por un músico es una maravilla pues gracias a una aplicación informática podremos ver la obra y escuchar la música. Las nuevas tecnologías permiten incorporar aplicaciones a mis obras que pueden mutar y aportar significados nuevos. Mis óvalos, por ejemplo, se transformarán en la pantalla de tu móvil, tendrán vida propia por sí solos y se convertirán en otra cosa más completa, más rica, más comunicativa.

El arte no es un elemento cerrado. Para mí el arte es algo total, como hacían los clásicos. Durante mi estancia en la Academia Española de Bellas Artes en Roma hacíamos reuniones donde unos aportaban sus composiciones musicales, otros hablaban de sus arquitecturas; viajábamos juntos y aprendí a convivir y colaborar con otros artistas y otras disciplinas. Conjugar disciplinas es muy enriquecedor e interesante.

La tecnología puedo aprenderla, pero la vida no es tan larga como para saberlo todo. Lo que sí tienes que saber es el hilo conductor de lo que quieres hacer, de lo que tu obra tiene que ser. Tu obra no puede ser un postizo, algo que le colocas y alguien comenta: “iMira qué moderno! ¡Mira qué bonito», sino que se debe crear y generar una sintonía que permita que determinadas técnicas conjuguen y tengan su interés -porque si carece de interés, no sirve.

N A: Tu firma VCANO llama la atención desde una perspectiva de género.

V C: Mi obra no habla de temas de género. Hablo de la ecología, de la naturaleza del ser humano sin diferenciar hombre o mujer; hablo del viaje interior independientemente de ser mujer o ser hombre. No necesito decir que soy mujer, más bien algunas veces me contraría tener que decir que soy mujer. En ocasiones me desquito y me desmonto para no ser centro de las miradas porque deseo que se fijen en la obra. De alguna manera huyo de los tópicos de la mujer artista. En mi obra hablo de que la huella es única y exclusiva; es un dispositivo único de identidad -ni tan siquiera los gemelos tienen la misma huella digital. Pero al mismo tiempo parecen todas la misma por ello es una metáfora de la igualdad. Pienso que la huella de la mujer tiene tanta importancia como la huella del hombre. Todos somos importantes y todos contamos a la hora de dejar nuestra huella, de cambiar algo para mejorar nuestra realidad y dejar un mundo mejor a las futuras generaciones. Eso es lo que yo quiero transmitir. 
Para contestar a tu pregunta me remonto a mi primera exposición en la década de los 70. Un galerista me dijo: «Me encanta tu trabajo, me gusta muchísimo, pero por favor no pongas Victoria Cano pon VCANO». En ese momento yo estaba estudiando, sería el año 77 o 78. Ante tal comentario, pregunté a qué obedecía y su respuesta fue: «Tu obra va más allá de lo que es una obra masculina o femenina; y cuando vean tu obra verán el arte. Es más, que no sepan si es de hombre o de mujer. Que vean primero la obra y luego pregunten de quién es». Sus palabras calaron y por eso firmo VCANO mis cuadros pues quiero que la gente vea primero mi obra y después, por supuesto, que conozcan a la artista. Hoy, afortunadamente, a las artistas ya no se les puede decir eso sino todo lo contrario, que firmen como quieran.

Hay arte, hay sensibilidades, no hay un arte de hombre o un arte de mujer, mi bagaje es trabajo y esfuerzo. Las mujeres artistas somos más generosas, tendemos a pasar desapercibidas. Muchas artistas de generaciones anteriores carecían de independencia económica para poder crear. Yo estudié, oposité, saqué mi plaza, tengo un trabajo remunerado y puedo permitirme el lujo de pintar lo que se me antoje. En este oficio lo más importante es darlo todo cada día; no hay que acomodarse ni conformarse. Quizá si lo das todo, a lo mejor recibes - no debemos quedarnos sin intentarlo.

V Z: Tu obra ha viajado a otros países como Bangladés, Corea del Sur, China, Estados Unidos, Italia, Alemania. ¿Qué te aportan esos viajes exteriores?

V C: Como os he comentado los viajes interiores y exteriores son para mí una constante. Mi obra ha sido seleccionada para participar en diversos eventos internacionales que han sido grandes experiencias. Me han aportado mucho a pesar de no entender su idioma pues el arte me permite acercarme, aproximarme, fusionarme de alguna forma con otras culturas, con otras texturas, con otros materiales, con otros paisajes. En esos nuevos y exóticos paisajes que visito veo perfiles en los árboles, en las nubes, en el agua. Cada día, esté donde esté, respiro la energía, la noto en mi piel. La energía es tan compleja, tan difícil de explicar, que necesito de la luz, del color, de los cambios de luz, la tengo que acompañar de proyecciones porque al final quiero llegar a un amplio grupo de espectadores independientemente de dónde procedan, de cuál sea su cultura. He de crear niveles de profundidad para que la primera sea una lectura fácil, una lectura sencilla.

V Z: Así pues la clave para poder conectar y hablar a muchos espectadores de distinta procedencia se halla en los distintos niveles de comprensión y de profundidad de tu obra.

V C: En Paisaje humano en rojos (2015) [fig. 18] a quienes les guste el color, quizá solo vean un cuadro de color rojo. Pasarán desapercibidos los perfiles, las huellas. Pero el color rojo tiene -como os comentaba antes cuando veíamos Piel de Amapola (2008) [fig. 19] o Tierra de amapolas (2008-2010) [fig. 20]- la misma fuerza y energía con la que te aproximas a un campo de amapolas. Si nos acercamos podremos experimentar no solo la fuerza del color, su energía, su belleza sino también su sutileza, su fragilidad, su fugacidad. Si coges una amapola, te quedas con su huella. Al tocarla dibujas tu huella digital en el pétalo de la amapola. Hay fuerza, hay vida pero también hay fragilidad. La materia se transforma, se metamorfosea. Ese es un ejemplo de muchas capas, de los distintos niveles de profundidad e invito a quien quiera profundizar que lo haga y a quien prefiera quedarse en la superficie, que disfrute de la fuerza y belleza del color. 


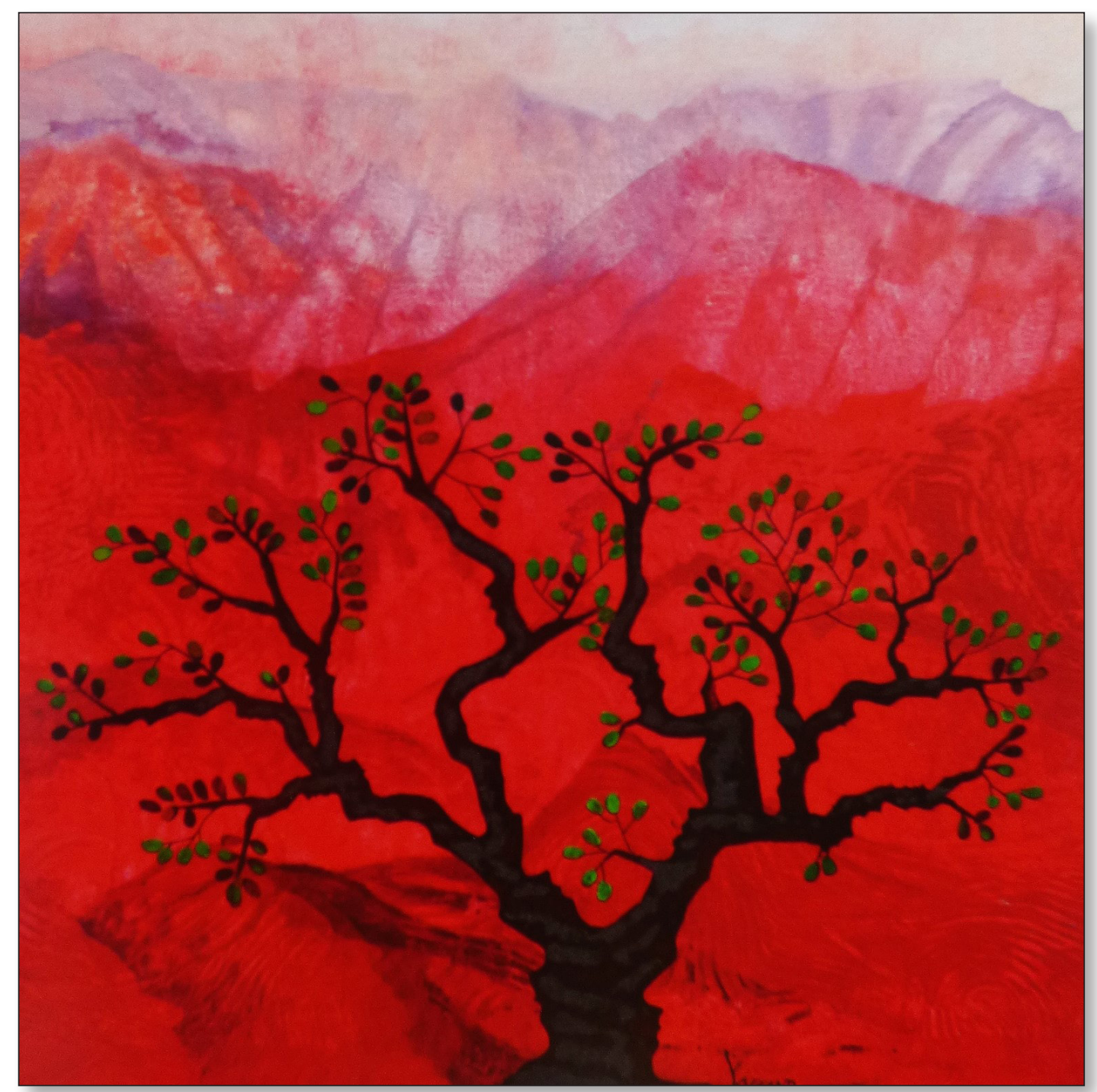

Fig. 18. Paisaje humano en rojos.

IMAGO, NÚM. I0, 2018, 99-124 


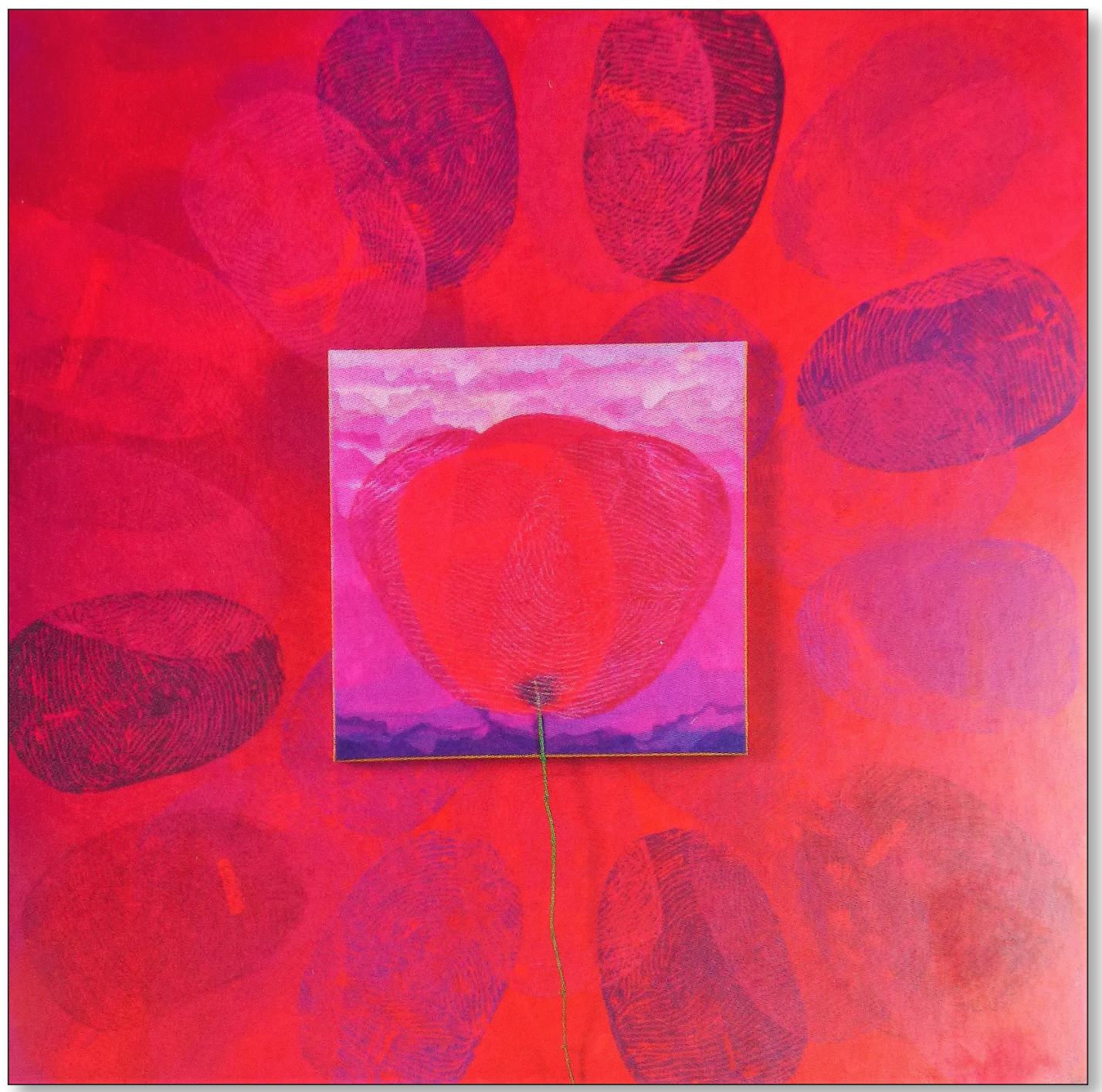

Fig. 19. Piel de amapola. 


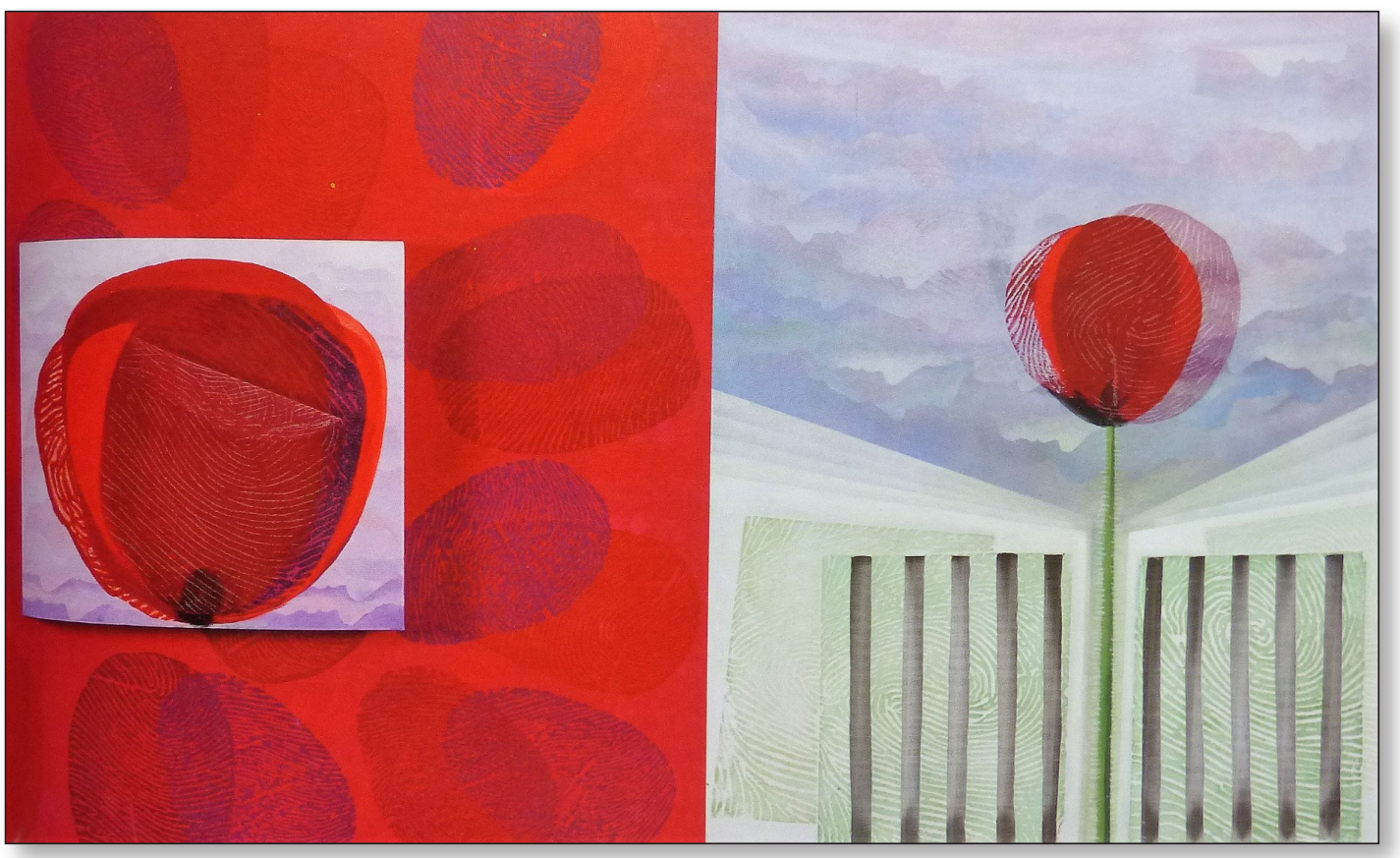

Fig. 20. Tierra de amapolas (fragmento).

N A: Energía, mucha energía es lo que nos has transmitido Victoria. Tu máxima es «transmitir emociones", y hoy lo has conseguido. Con tus obras hemos volado, hemos soñado, hemos sentido. Por eso queremos invitar a quienes no la conocen a dejarse arrastrar por ese tsunami de huellas, perfiles, texturas, colores, luz. Que sean parte de él pues son fruto de la pasión, del cariño y del respeto, de un trabajo bien hecho. Viajar al fondo de la naturaleza humana en continua transformación es un reto que nos lanzas.

V C: Como artista creo que debemos generar belleza para alcanzar la armonía entre todo lo vivo por difícil que esta empresa sea.

\section{BIBLIOGRAFÍA}

Blanco, V. [2010]. "El poder de la huella», <http://vcano.com/el-poder-de-la-huella2010-venancio-blanco/>.

Blasco Carrascosa, J.Á. [1990]. «Una aproximación a la pintura posmoderna de Victoria Cano», en VCANO Pinturas, Nave Diez Talleres de Arte, Valencia.

Caballero Guiral, J. [2018]. "Victoria Cano: un viaje a través de los sentidos», en La huella de los sentidos, Imprenta Canós, S.L., Villarreal (Castellón).

Cueto Lominchar, J. L. [2007]. «El color de la huella», <http://vcano.com/el-color-de-lahuella-2007-jose-luis-cueto-lominchar/>.

De la Calle, R. [2001]. "Victoria Cano, entre imágenes, huellas y metáforas», en Victoria Cano. Diálogo de sucesos, Ayuntamiento de Valencia, Valencia.

IMAGO, NÚM. 10, 2018, 99-124 
De la CALLe, R. [2004]. "Algunas reflexiones sobre la trayectoria y las aportaciones actuales de Victoria Cano", en Preposiciones de energía de Victoria Cano, CEU San Pablo, Valencia,

De la Calle, R. [2016]. «Victoria Cano. Ensoñaciones desde la lejanía (I), Ensoñaciones para la lejanía (II) y Ensoñaciones contra la lejanía (III)», en Ecos y huellas. Desde el Trastevere al Carmen, Consorcio de Museos de la Comunitat Valenciana, Valencia.

De Ulierte, L. [2006]. "La identidad cambiante», en Laberintos de Identidad, Universidad de Jaén, Jaén.

García de Ángela, J. L. [1996]. "Tránsito de la energía», en Victoria Cano, Museo Torres García, Montevideo (Uruguay).

Garnería, J. [1998]. "Horizonte de sucesos», en Victoria Cano. Horizonte de sucesos, Ajuntament de Valéncia, Valencia.

GARnería, J. [2007]. «El color de la huella», <http://vcano.com/el-color-de-la-huella-2007/>.

Ledesma Pedraz, M. [2006]. «Presentación». Laberintos de Identidad, Universidad de Jaén, Jaén.

Peiró, J.B. [2006]. «El laberinto de la soledad», en Laberintos de Identidad, Universidad de Jaén, Jaén.

Torrent Esclapés, R. [2018]. "Victoria Cano: el libro y la imprenta», en La huella de los sentidos, Imprenta Canós, S.L., Villarreal (Castellón).

Urbano, M. [1999]. «El trallazo de sentir». Victoria Cano, Diputación de Jaén, Jaén. 